\title{
Stability of "Support-Surrounding Rock" System for Fully Mechanized Longwall Mining in Steeply Dipping Coal Seams
}

\section{Luo Shenghu}

Xi'an University of Science and Technology

tong wang ( $D$ 670298140@qq.com)

Xi'an University of Science and Technology https://orcid.org/0000-0001-8413-6826

Wu Yongping

Xi'an University of Science and Technology

Huangfu Jingyu

Xi'an University of Science and Technology

\section{Zhao Huatao}

Shandong Medical Imaging Research Institute

\section{Research}

Keywords: inverted triangular hollow surface, non-uniform filling zone, steeply dipping coal seam, stability, "support- surrounding rock" system

Posted Date: April 13th, 2021

DOl: https://doi.org/10.21203/rs.3.rs-403141/v1

License: (c) (1) This work is licensed under a Creative Commons Attribution 4.0 International License. Read Full License 


\title{
Stability of "Support-Surrounding Rock" System for Fully Mechanized
}

\section{Longwall Mining in Steeply Dipping Coal Seams}

\author{
Luo Shenghu $^{\mathrm{a}, \mathrm{b}}$, *Wang Tong ${ }^{\mathrm{b}, \mathrm{c}}$, Wu Yongping ${ }^{\mathrm{b}, \mathrm{c}}$, Huangfu Jingyu ${ }^{\mathrm{b}, \mathrm{c}}$, Zhao Huatao ${ }^{\mathrm{d}}$ \\ a. Department of Mechanics, Xi' an University of Science and Technology, Xi'an, 710054, China \\ b. Key Laboratory of Western Mine Exploitation and Hazard Prevention Ministry of Education, Xi'an University \\ of Science and Technology, Xi' an 710054, China \\ c. School of Energy Engineering, Xi'an University of Science and Technology, Xi'an 710054, China \\ d. Shandong Mining Machinery Group Co., Ltd. \\ *Corresponding author: [670298140@qq.com]
}

\begin{abstract}
The key to the safe and efficient longwall mining of steeply dipping seams lies in the stability control of the "support-surrounding rock" system. This paper analyzes the difficulty of controlling the stability of the support during the longwall mining process of steeply dipping coal seams in terms of the characteristics of the non-uniform filled-in gob using a combination of physical test, theoretical analysis and field measurements. Considering the floor as an elastic foundation, we built a "support-surrounding rock" mechanical model based on data obtained on "support-surrounding rock" systems in different regions and the laws of support motion under different load conditions. Our findings are summarized as follows. First, depending on the angle of the coal seam, the caving gangue will roll (slide) downward along the incline, resulting in the formation of a non-uniform filling zone in the deep gob in which the lower, middle, and upper sections are filled, half-filled, and empty, respectively. In addition, an inverted triangular hollow surface is formed on the floor of the gob in the middle and upper sections behind the support. Furthermore, as the angle of the coal seam, length of the working face, and mining height increase, the characteristics of the non-uniform filled-in gob are enhanced. Second, we found that, as a result of support by the gangue, the "support-surrounding rock" system is relatively stable in the lower part of the working face while, in the middle and upper sections of the working face, the contact method and loading characteristics of the support are more complicated, making stability control difficult. Third, the magnitude and direction of the load, action point, and mining height all affect the stability of the support to varying degrees, with the tangential load and action position of the roof load having the most significant impacts on the stability of the support. Under loading by the roof, rotation and subsidence of the support inevitably occur, with gradually increasing amplitude and effects on the inter-support and sliding forces. Finally, we found that it is advisable in the process of moving the support to adopt "sliding advance of support" measures and to apply a "down-up" removal order to ensure overall stability. These research results provide reference and guidance of significance to field practice production.
\end{abstract}

Keywords: inverted triangular hollow surface; non-uniform filling zone; steeply dipping coal seam; stability; "supportsurrounding rock" system

\section{Introduction}

Steeply dipping coal seam are seams with angles from the horizontal in the range of $35-55^{\circ}$. Such seams, which are recognized worldwide as being difficult to mine, are widely distributed throughout major mining areas in China, accounting for $10-20 \%$ and $5-8 \%$ of China's coal reserves and output, respectively[1]. More than $50 \%$ of the mines with steeply dipping coal seams occur in western China (e.g., Sichuan, Guizhou, Gansu, Xinjiang, Ningxia Provinces, and other mining areas). The country's long history of high-intensity mining has made coal reserves with "excellent" occurrence conditions increasingly rare, and many mines have had to resort to the mining of steeply dipping coal seams with relatively complicated occurrence conditions in the eastern and central mining areas (e.g., Shandong, Hebei, Anhui, and Shanxi Provinces). Thus, the mining of steeply dipping coal seams has become a major engineering problem in the development of China's coal resource[2,3]. 
The coal-forming environment of steeply dipping coal seams is complicated, and such seams are extremely difficult to safely and efficiently mine. In the 1970s, the Soviet Union developed fully mechanized mining technologies for mining thick, medium-thick, and steeply dipping coal seams[4,5]. In the 1980s and 1990s, the United States, Germany, France, United Kingdom, India, Spain, and other countries also explored mechanized mining methods and ground control techniques for accessing steeply dipping coal seams and used these to carry out limited experimental mining $[6,7,8,9]$. The steeply dipping coal seams in China, which carries out the most coal mining of any country in the world, cover a rich reserve base and a large area. After nearly two decades of research and development, China has made significant progress in developing the mining theory, technology applications, and equipment needed to mine steeply dipping coal seams, successfully achieved a transformation from non-mechanized mining to fully mechanized longwall mining (fully mechanized caving) under certain conditions, and solved the basic safety problem of mining in steeply dipping seams[10]. However, with the exception of some mines in which the fully mechanized mining of medium-thick coal seams or the fully mechanized caving of some extra-thick coal seams takes place, mines are in general still using non-mechanized mining methods such as oblique short-wall and longwall mining. In such mines, low production and efficiency, poor safety and operating environments, and frequent casualty-inducing accidents remain important factors restricting production and operation[1,10].

The key to the safe and efficient longwall mining of steeply dipping coal seams is the effective control of surrounding rock, which is made difficult by the need to enact proper stability control of the "support-surrounding rock" system[11]. In the mining of steeply dipping coal seams, the high coal seam angle makes the control of roof breaking movement and support and equipment and floor failure sliding extremely complicated[12]. This complexity changes the "support-surrounding rock" system of the working face from a "stable state" system in the conventional sense to an "unstable state" system[13]. In general, the control extended to the support must not only control the roof through the working resistance but also, through the application of working resistance, the floor and the control system itself. In recent years, a number of methods, including theoretical analysis, numerical calculation, simulation with physically similar materials, on-site monitoring, etc., have been developed to understand, for example, the migration law of surrounding rock and support loading characteristics, the coupling mechanism of the "support-surrounding rock" system[14,15,16,17], the mechanism of variation and instability[18,19,20], and inter-support pushing and its cumulative effects under various mining methods (e.g., longwall mining of steeply dipping medium-thick coal seams, fully mechanized longwall caving of thick coal seams, coal seam group mining)[ 21,22,23,24]. A range of determinate conditions for support stability and methods for calculating the critical working resistance of the support have been derived and many technical measures for the prevention of slipping of the hydraulic support have been proposed, with the results promoting the continuous progress of the control theory and technology for ensuring support stability in steeply dipping coal seam mining.

However, the previous research on support stability has focused primarily on experiments and field monitoring, with some theoretical research done to primarily determine the working resistance of the support under critical rotating and sliding conditions based on support stability criteria constructed without consideration of floor deformation and the assumption that the floor is a rigid body. In the mining process of steeply dipping coal seam, the deformation and failure of the working face roof has a complicated action mode on the support, and the mechanical behavior and state of the support in different areas will change greatly. Especially in the middle and upper areas of the inclined, the roof deforms and breaks frequently, the support is prone to no-load and unbalanced load, and the rotates, slides, and squeezes between the supports frequently. In severe cases, the paralysis of support system caused by local support instability can easily induce large-scale surrounding rock disasters, causing a large number of casualties and economic losses. Unfortunately, to date there has been no research work to address this problem. Therefore, it is particularly important to reveal the surrounding rock movement law of longwall working face in steeply dipping coal seam and its response mechanism to support mechanical behavior, and to propose support dynamic stability control measures.

In this study, an analysis of the breaking and moving laws of the surrounding rock and the basic characteristics of the surrounding rock structure formed in the longwall mining of steeply dipping coal seams was conducted. Under the 
assumption that the floor is an elastic foundation, a mechanical model of the "support-surrounding rock" system and the behavioral response of the support under the roof load was derived. The results provide a theoretical reference value for solving the dynamic stability control of the "support-surrounding rock" system in the longwall mining of steeply dipping coal seams.

\section{Background}

\subsection{Geological condition}

Working face 25221 of coalmine 2130 (Xinjiang Coking Coal Group Ewirgol) is located in district 2 of the \#5 coal seam. The working face is located west of ditch \#15 ditch and $153 \mathrm{~m}$ east of line 16 . The surface is mountainous and filled with gullies. The working face has a long and narrow distribution from east to west. The mining elevation is $+2047-2120 \mathrm{~m}$, the strike length is $2098 \mathrm{~m}$, and the inclined length is $100 \mathrm{~m}$. The angle fluctuates within $36^{\circ}-46^{\circ}$ with an average of $45^{\circ}$. The coal bulk density is $1.35 \mathrm{t} / \mathrm{m}^{3}$. The coal seam is stable with a thickness of $3.58-9.77 \mathrm{~m}$ and average thickness of $5.77 \mathrm{~m}$. The hardness coefficient $f$ of the coal is $0.3-0.5$. The spontaneous combustion tendency is $\Delta T=9-14^{\circ} \mathrm{C}$; this is less than $20^{\circ} \mathrm{C}$, which indicates grade IV coal. The explosiveness index of the coal dust is $V_{\mathrm{r}}=$ $24 \%-45 \%$; this is in the range of $0.1-1.0$, which indicates medium explosiveness. The gas emission volume is $1.52-$ $4.62 \mathrm{~m}^{3} / \mathrm{t}$, which indicates an abnormal gas mine.

\subsection{Field monitoring of working resistances}

The workings at the 25221 working face of the 2130 coal mine adopt a fully mechanized large-height mining method with the following process flow: cutting coal downward $\rightarrow$ clearing floating coal upward $\rightarrow$ pushing conveyor $\rightarrow$ moving support. According to the special geological conditions of the mine, the working resistance of the support

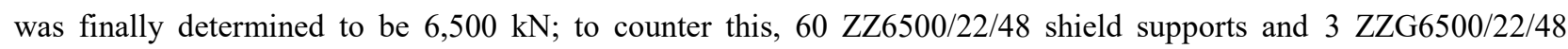
transition supports are used. The rock pressure on the working face was observed with a KJ377 pressure dynamic detector. The \#9, \#29, and \#47 supports in the inclined lower area, inclined middle area, and inclined upper area, respectively, were monitored, with the monitoring results shown in Fig 1.
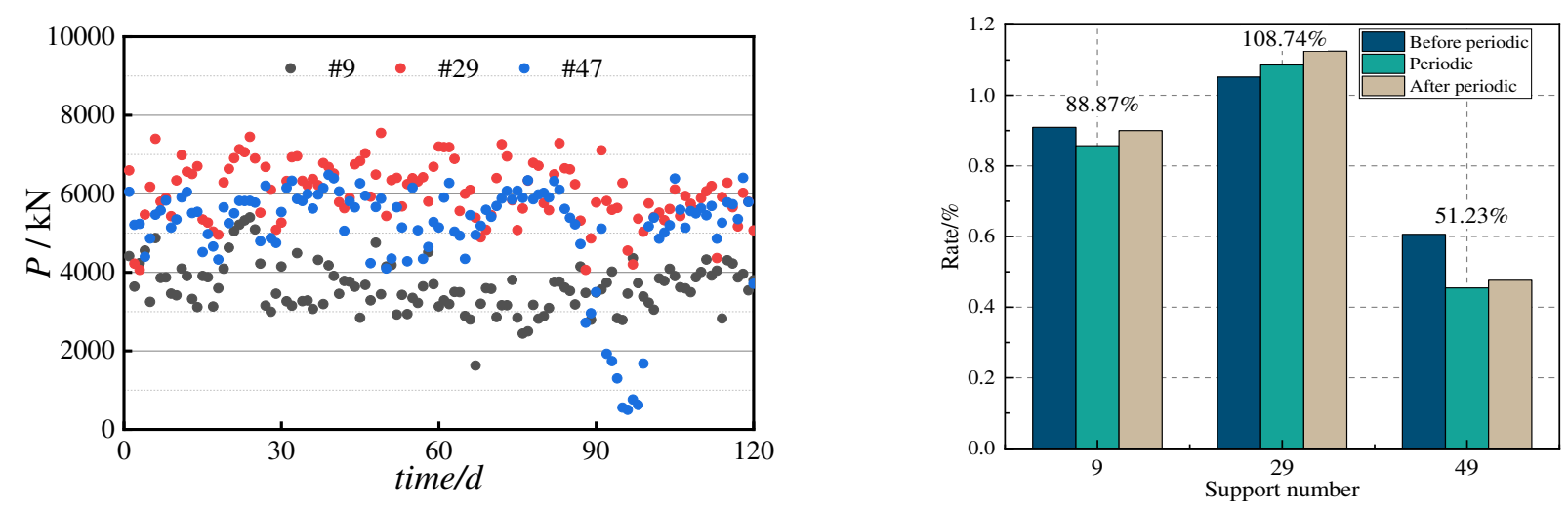

(a) support resistance; (b)load ratio of back to front leg

Fig. 1 Support resistance and load ratio of back to front leg in different areas

The following observations are made from the monitoring results:

(1) The average working resistance of the \#9 support is 3,505 $\mathrm{kN}$, while the maximum working resistance during periodic weighting is $5,400 \mathrm{kN}$, with a standard deviation of $767.12 \mathrm{kN}$. The average working resistance and maximum working resistance during periodic weighting of the \#29 support are 6,422 and 9,390 kN, respectively, with a standard deviation of $1,358.17 \mathrm{kN}$. The average working resistance and maximum working resistance during periodic weighting of the \#47 support are 4,985 and 6,481 kN, respectively, with a standard deviation of 1,088.07 kN. 
(2) The load distribution on the front and back leg of the support is different in different areas. In lower area, the load distribution on the front and back leg of the support is more uniform, and the load of the front is larger than that of the back leg. The load ratio of the back to front is $90.9 \%, 85.71 \%$, and $90 \%$ during the before, during and after the periodic weighting, and the average load ratio is $88.87 \%$. In middle area, the load distribution of the front and back leg of the support is relatively uniform, and the load of the back is greater than that of the front leg. The load ratio of the back to front is $105.15 \%, 108.57 \%$, and $112.5 \%$ respectively, and the average load ratio was $108.74 \%$. In upper area, the load distribution of the front and back leg of the support is uneven, and the load of the back is much smaller than the front leg. The load ratio of the back to front was $60.61 \%, 45.45 \%$, and $47.62 \%$ respectively, and the average load ratio was $51.23 \%$.

(3) There are obvious unbalanced load characteristics in the support on the working face. Along the incline, the load has the basic characteristics of being largest in the middle area, followed in succession by the upper and lower areas. In the lower area of the working face, the amplitude of the load is essentially constant and the "supportsurrounding rock" system is relatively stable. In the middle and upper areas of the working face, the support is susceptible during periodic weighting to the impact of the roof, which exceeds the rated working resistance. Some supports bear very little load, which leads to a lack of elements in the "support-surrounding rock" system, or the formation of a "pseudo system." The "support-surrounding rock" interaction is complicated, and there are obvious pushing and biting phenomena between the supports.

\section{Interaction between support and surrounding rock}

Physically similar materials experiments are used to study the deformation and failure of surrounding rock. A coal and rock layer histogram was used to reduce the coalmine to an experimental model with a geometric similarity ratio of 1:20. The physical and mechanical parameters of the coal and rock mass measured onsite were used to determine the proportions of similar materials: 70-140 mesh quartz sand, coal ash, gypsum, and calcium carbonate. Water was added, and the materials were mixed evenly and placed in the model frame. A heavy object was used to compact the material to the required density. To represent the layers, 8-20 mesh mica powder was used. According to the law of similarity, the stress and strength similarity constant was 32 , the time similarity constant was $20^{1 / 2}$, the bulk density similarity constant was 1.6 , and the load similarity constant was 12800 . The proportions of similar materials are shown in Table 1 , and the model is shown in Fig. 2.

Table 1 The proportions of similar materials

\begin{tabular}{ccccc}
\hline Layer & Rock & Thickness $(\mathrm{m})$ & Thickness of model $(\mathrm{cm})$ & Proportion \\
\hline $\begin{array}{c}\text { Main roof } \\
\text { Immediate } \\
\text { roof }\end{array}$ & $\begin{array}{c}\text { Medium sandstone } \\
\text { Gravelly coarse } \\
\text { sandstone } \\
\begin{array}{c}\text { Coal seam } \\
\text { Immediate }\end{array}\end{array}$ & 17 & 85 & 846 \\
$\begin{array}{c}\text { floor } \\
\text { Main floor }\end{array}$ & Coarbon mudstone & 17.32 & 16 & 828 \\
\hline
\end{tabular}



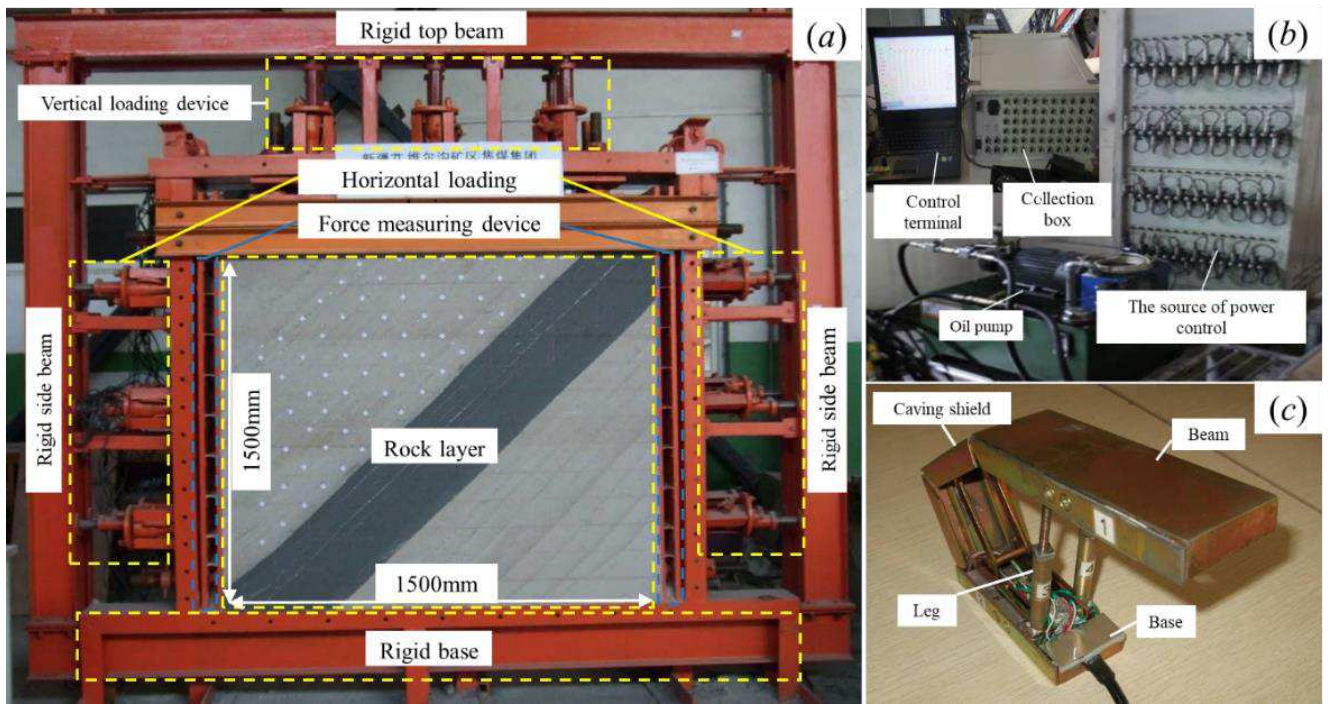

(a) Model; (b) Date collection system; (c) Support model

Fig.2 Test model

\subsection{Characteristics of surrounding rock migration}

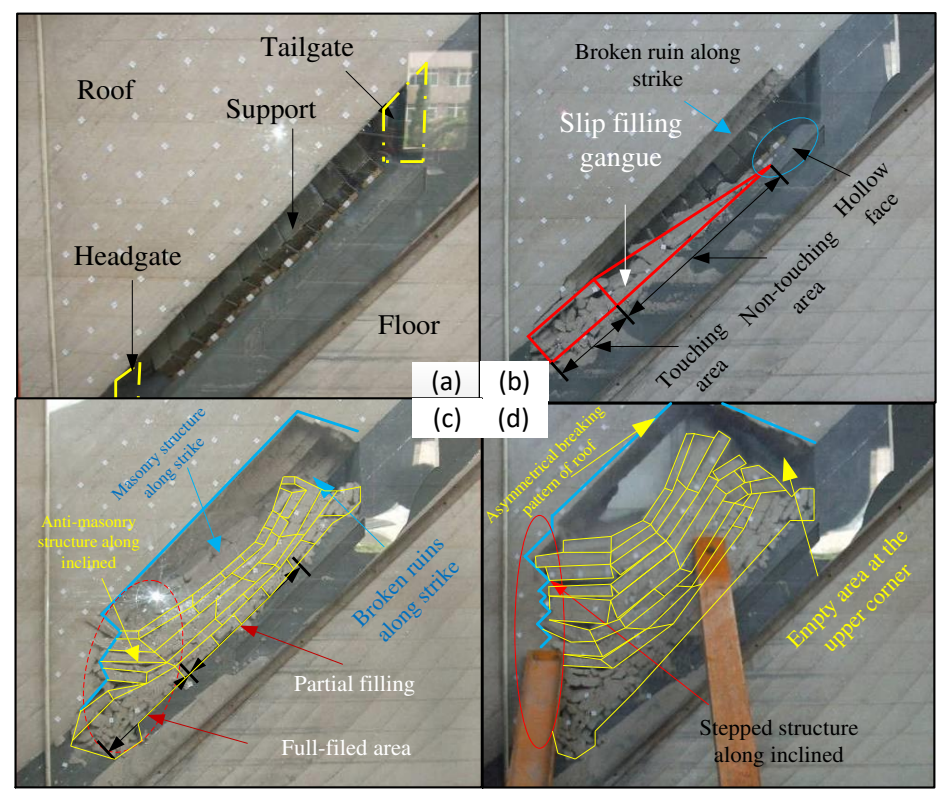

Fig.3 Characteristics of caving and filling of floor

The result is shown in Figure 3:

(1) The movement of roof is asymmetrical. Generally, the displacement of the upper area is larger and the lower area is smaller. There are also differences in the failure mode. The failure mode of the upper area is generally "tensileshear" failure, and the lower area is generally "compression-shear" failure.

(2) Along the strike of the working face, the main roof will form an articulated rock beam structure of different lengths in different areas. In the lower area of the working face, the gob is relatively full, the gangue filling body is dense, the main roof is longer, and the amount of sinking and rotation is small. The strength of mining pressure is relatively small, the step distance is the largest, and there is even no obvious periodic characteristic. The caving of roof in this area is inadequate, and there is no obvious characteristic of "three-zones". In the middle area of the working face, the gob is partially filled, the length of main roof is relatively short, but the broken main roof can also form an articulated rock beam structure. The amount of sinking and rotation is large. The strength of mining pressure is relatively large, the step distance is the large but less than lower area, and there is an obvious periodic characteristic. In the upper area of 
the working face, the gangue slides down along the inclined, and a hollow face is formed on the bottom of the gob in a certain range behind the support. Affected by this, the surrounding rock migration space in this area is large, the articulated rock beam structure cannot be formed after the main roof broken, the length of the main roof is short, the strata behavior appears frequently, but the strength is moderate. The strata caved sufficiently, and the "three zones" formed a high level. On the whole, the broken roof along the strike is deep and short in the upper area and shallow and long in the middle and lower area. In the deep gob where the roof is fully caved, a non-uniform filling zone is formed with the lower part full-filled, the middle part partial filled, and the upper part empty. In the middle and upper areas of the gob along inclined behind the support where the roof has not fully caved, an inverted triangle hallow face is formed.

(3) Along the inclined of the working face, the gangue slip filling from the immediate shows the characteristics of from dense to loose: The lumpness of the gangue in the lower part is graded with each other, the filling is dense and the strength is greater. The gangue in middle and upper area has a large block size, loose filled and low strength. A masonry and anti-masonry structures along the inclination formed when the rotational deformation failure occurred in the main roof. In upper area, the caving roof slides downwards along the floor of the working face, forming an empty area in the upper corner. In middle area, the rock block rotation acts on the support, causing the support's working resistance to increase. In lower area, the area is filled up after the immediate roof caving. The roof migration space above the coal seam in this area is small, and the amount of rotation and subsidence is smaller than that of the middle and upper area. The rock mass is piled up as an anti-masonry structure.

\subsection{Non-uniform filling characteristics of caving gangue}

Combined with the above experimental results, it can be seen that: In the mining of a steeply dipping coal seam, the angle of the coal seam will be greater than the natural resting angle of the caving gangue, inducing the gangue to slide down to fill the lower area of the working face along the incline, as shown by the black arrow in Fig 4 . The portion of the main roof that caves in the middle and upper areas of the deep gob will also slide down, as shown by the red arrow the figure. In the deep gob, a non-uniform filling zone in which the lower, middle, and upper areas are filled, halffilled, and empty, respectively, is formed, while an inverted triangular hollow face is formed on the floor in the middle and upper areas behind the support, as shown in Fig 4. It is seen that the filling characteristics of this gob will have, in addition to obvious asymmetric characteristics, anisotropy along the strike. These asymmetries lead to significant differences in the characteristics of the loading and failure movement of the surrounding rock and the interaction relationship between the "support-surrounding rock" system along the inclined and strike directions.

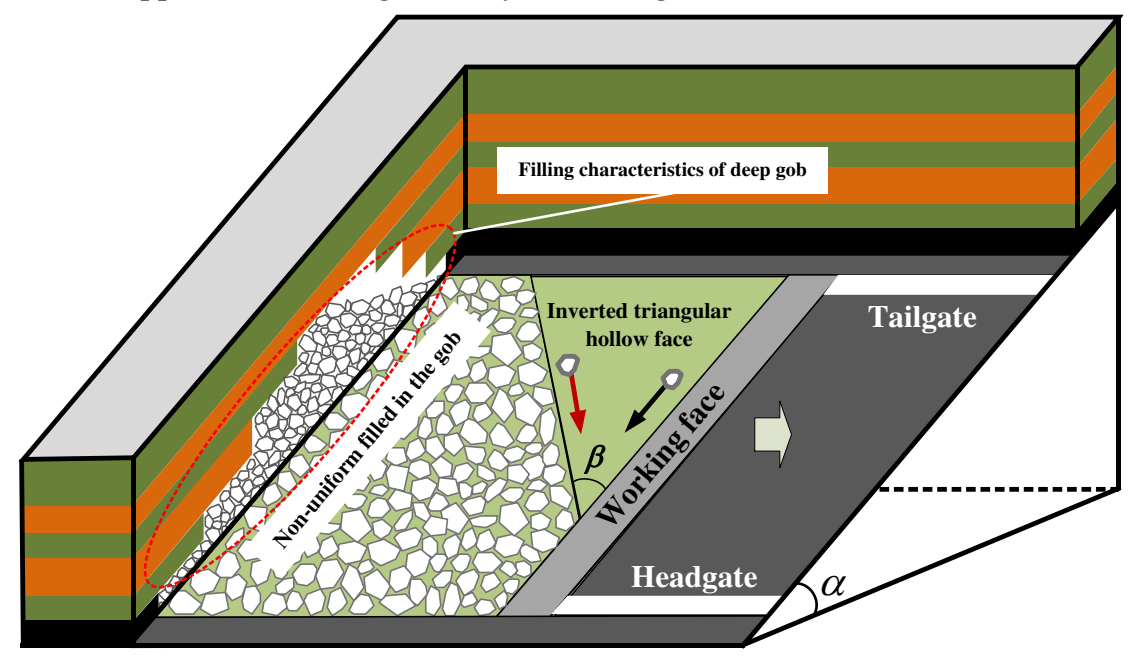

Fig.4 Filling characteristics of the gob

Figure 5 shows the filling characteristics of the gob behind the support. In the figure, the x-axis runs along the strike, while the $y$ - and z-axes point downward along the incline on the working face and upward along the vertical coal seam, respectively. The length of the working face $(L)$, thickness of the coal seam $\left(h_{0}\right)$, thickness of the immediate roof 
$\left(h_{l}\right)$, inclined length of the rectangular area of the caving gangue filling body behind the support $(a)$, inclined length of the triangular area of the caving gangue filling body behind the support $(b)$, and inclined length of the inverted triangle in the middle and upper area behind the gob $(c)$ are all given in meters; the angle of the coal seam $(\alpha)$, resting angle of the gangue $(\gamma)$, and angle between the contact line of the support and the floor and the contact line of the gangue and the floor $(\beta)$ are all given in degrees.

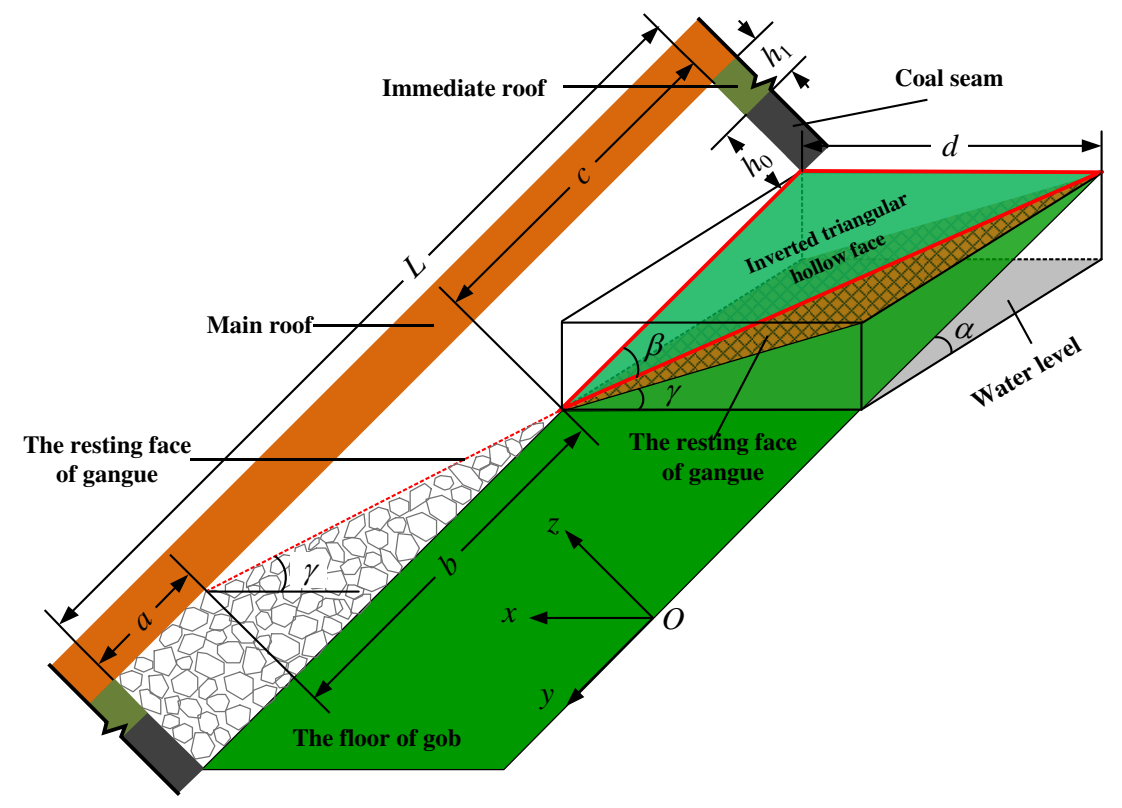

Fig.5 Schematic of gob-filling characteristics

For convenience in obtaining a theoretical solution, it is assumed that the gob behind the support in the middle and lower areas is filled with caving gangue as an immediate roof rock block. From the filling characteristics of the gob behind the support shown in Figure 5, the relationship between the immediate roof caving gangue and the filling gangue can be described as

$$
k L h_{1} \cdot 1=a\left(h_{0}+h_{1}\right) \cdot 1+\frac{b\left(h_{0}+h_{1}\right)}{2} \cdot 1
$$

where $k$ is the bulking factor. From the geometric relationship shown in Figure 5, the inclined length, $b$, of the triangular area of the gangue filling body behind the support is

$$
b=\left(h_{0}+h_{1}\right) \cot (\alpha-\gamma)
$$

Substituting Eq. (2) into (1), the inclined length, $a$, of the rectangular area of the gangue filling body in the gob behind the support can be expressed as

$a=\frac{L h_{1} k}{h_{0}+h_{1}}-\frac{\left(h_{0}+h_{1}\right)}{2} \cot (\alpha-\gamma)$

Similarly, the inclined length, $c$, of the inverted triangle in the middle and upper area of the gob behind the support can be expressed as

$c=L-\frac{L h_{1} k}{h_{0}+h_{1}}+\frac{\left(h_{0}+h_{1}\right)}{2} \cot (\alpha-\gamma)$

From the geometric relationship between the gangue filling body and the hollow face in the inclined middle and upper areas in Figure 5, the angle, $\beta$, between the contact line of the support and the floor and the contact line of the gangue and the floor can be expressed as

$\beta=\arctan \frac{\sin \alpha}{\tan \gamma}$ 
Figure 6 shows the influence of the coal seam angle and the length of the working face on the filling characteristics of the gob behind the support. The values of the remaining parameters used in the calculation have been marked in the figure, while the dashed lines and corresponding labels indicate the values of these parameters when the inclined length, $c$, of the hollow face is zero. It is seen from the figure that the size of the hollow face of the floor behind the support increases with the coal seam angle and the length of the working face.

An inspection of Figure 6(a) reveals that, when the angle of coal seam is slightly larger than the natural resting angle of the gangue, that is, when the angle is between 35 and $38.5^{\circ}$, the rolling characteristics of the gangue do not manifest. In this case, the inclined length, $a$, of the rectangular area of the filling body and the inclined length, $c$, of the inverted triangle hollow face are both less than zero, and the gob tends to have an unfilled region in its lower area and no hollow face in its upper area. When the angle is between 38.5 and $42.5^{\circ}$, the length of the working face is less than $75.5 \mathrm{~m}$, the mining height is less than $2.98 \mathrm{~m}$, and the thickness of the immediate roof is greater than $4.70 \mathrm{~m}$, while the inclined length, $a$, of the rectangular area of the filling body is greater than zero and the inclined length, $c$, of the inverted triangle hollow face is less than zero. In this case, there is a filled-in region in the lower area of the gob behind the support and no hollow face in the upper area. When the angle is greater than $42.5^{\circ}$, the length of the working face and mining height is greater than 75.5 and $2.98 \mathrm{~m}$, respectively, and the thickness of the immediate roof is less than $4.70 \mathrm{~m}$. The values of $a$ and $c$ are both greater than zero, and the gob tends to have a filled-in region in its lower area and a hollow face in its upper area.

From Figure 6(b), it is seen that, when the angle of coal seam is $45^{\circ}$ and the length of the working face is less than $75.5 \mathrm{~m}$, a filling region is formed in the lower area of the working face, while the resting face of the gangue is covered in the middle and upper parts of the gob. When the length of the working face is greater than $75.5 \mathrm{~m}$, the values of $a$ and $c$ are both proportional $L$, the length of the working face.
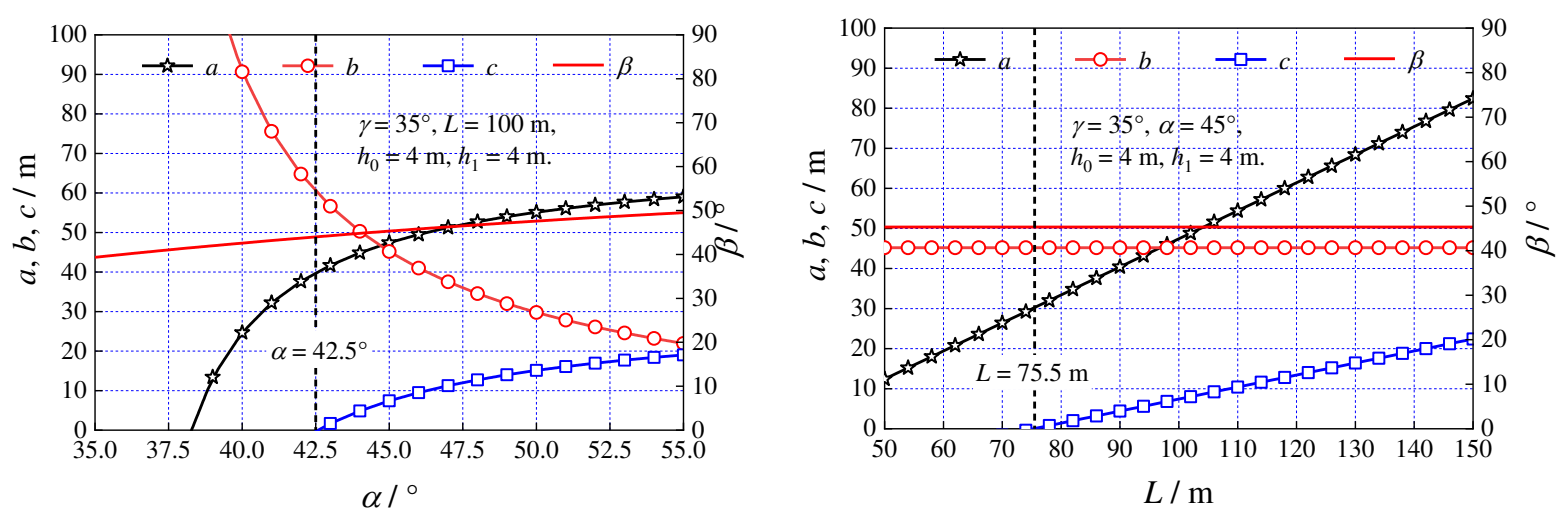

(a) Influence of angle $\alpha$ on filling characteristics; (b) Influence of length L on filling characteristics

Fig.6 Factors influencing gob filling characteristics

It is seen that, in the case of longwall mining of steeply dipping coal seams, the non-uniform filling characteristics of the caving gangue are closely related to factors such as coal seam angle and length of the working face; as these factors increase, the amplitude and severity of gangue rolling increases. The stability of the roof and floor in the lower part of the working face is enhanced by the support of gangue. As the working face advances, the main activity range of the roof and floor rock formations that are moved and destroyed is moved upward, the amplitude and severity of the roof and floor rock formations in the upper and middle areas of the working face increase, and the likelihood of floor damage slip and falling and rotation of the support and equipment falling increase sharply. The "support-surrounding rock" system is prone to dynamic instability during the advancement of the working face, which in turn can lead to failure of the surrounding rock.

\subsection{Interaction characteristics of "support-surrounding rock"}

The interaction relationship of the "support-surrounding rock" system along the strike and incline varies 
significantly with the non-uniform filling effect of the gangue, as shown in Figs. 7 and 8 . In the lower area of the working face, the gob is in a filled-in state in which there is a high filling density, limited space for migration of the surrounding rock, and minimal subsidence and rotational angles along the strike and incline. In this region, an articulated rock beam structure can be formed in the strike direction. There is a relatively complete immediate roof above the top beam of the support as a load transfer medium, which transfers the effect of the main roof and overburden layer to the support more evenly, which is also the main reason for the small difference in the load of the front and back legs of the on-site monitoring in Section 2.2. Nevertheless, because of the lateral rolling (sliding) movement of the caving gangue, the rear canopy of the support in the lower area is susceptible to the impact of the gangue.

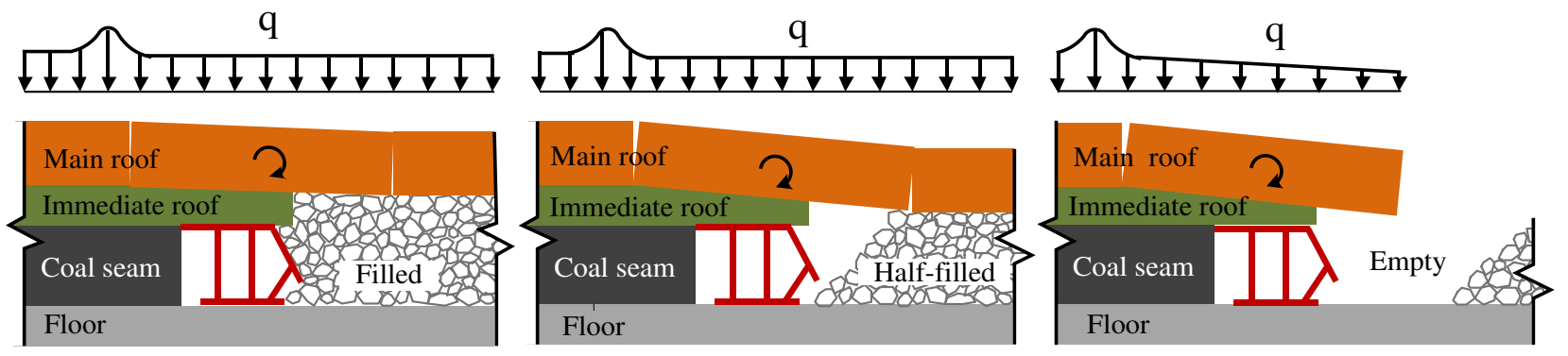

(a) Lower area of inclination;(b) middle area of inclination;(c) upper area of inclination

Fig.7 Interaction relationship of "support-surrounding rock" system along the strike

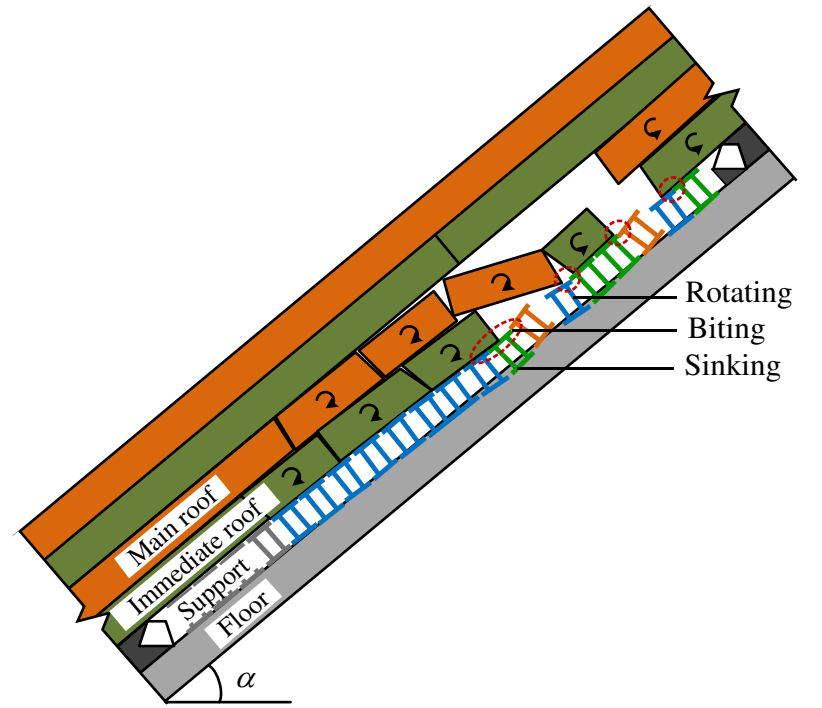

Fig.8 Interaction relationship of "support-surrounding rock" system along the inclined

In the middle area of the working face, the gob is in a half-filled state and the filling density is less than in the lower area. Although an articulated rock beam structure can still be formed along the strike following ejection of the main roof, its stability will be weaker than in the lower area. In addition, the increase of the space available for roof movement allows for large degrees of cut-off and rotation along the strike and incline directions following breaking of the main roof. The support is susceptible to impact loads. Immediate roof can transfer the overburden load to the support, but the substantial rotation of the main roof will cause the load point of the top beam of support to move backward. Therefore, the load of the back is slightly larger than front leg of the support, and the load values of the two legs are both larger. The stability of the "support-surrounding rock" system is poor.

In the upper area of the working face, a small amount of gangue is filled into the gob at a relatively large distance from the support. There is no gangue constraint behind the broken main roof, which tends to roll (slide) toward the middle and lower areas, and it is not possible to form an articulated rock beam structure along the strike. The residual immediate roof above the top beam of the support is shorter, and the load action point is at the front of the top beam. The load of the front is greater than the back leg, and the support is prone to "head down". The amplitude and severity of roof movement are both high, and the stability of the rock structure is poor. Following ejection of the main roof, the cut-off and rotation amplitudes along the strike and incline directions are much larger than in the middle area and, as 
the working face advances, instabilities caused by rotation and the formation of an empty roof are extremely likely. In the upper and middle areas of the working face, there are complex interactions in the "support-surrounding rock" system, phenomena such as eccentric and no-loading of the supports and biting between supports are prominent, and it is difficult to control the stability of the supports.
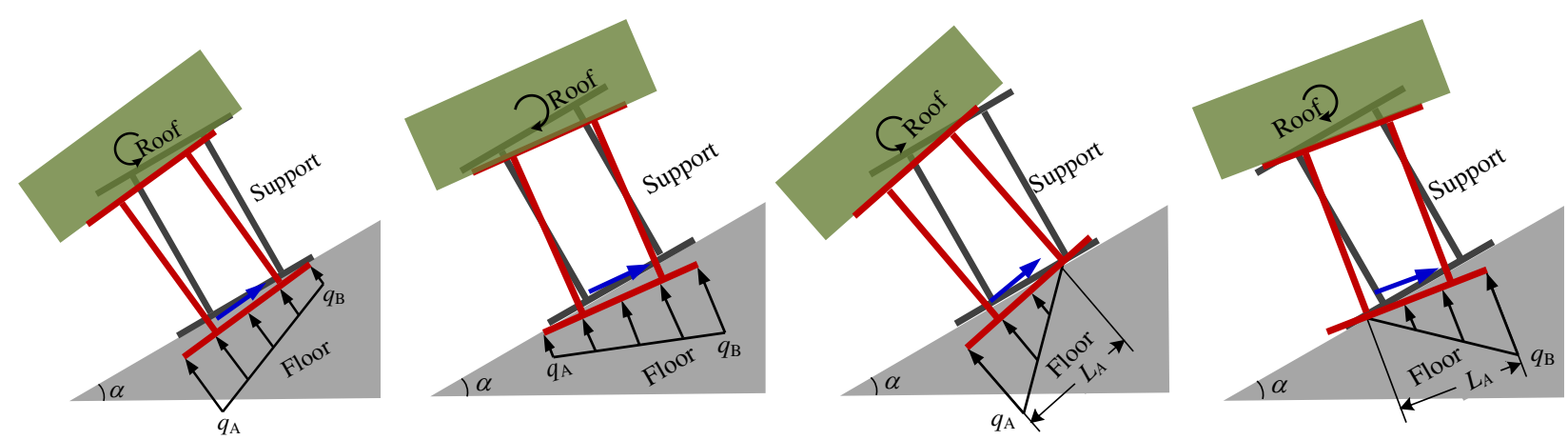

(a) Subsidence + reverse rotation ;(b) Subsidence + forward rotation; (c) Subsidence + reverse rotation + lift off ; (d) Subsidence + forward rotation + lift off

Fig.9 Interaction between the support and surrounding rock

When the movement state of the roof changes, the value, direction, and action point of the load on the support all change, and the support responds accordingly. When the support position changes, the interaction between the support and floor and the magnitude, direction, and point of action of the load on the support by the floor also change, as shown in Figure 9. It is seen that, in the mining of steeply dipping coal seams, when the roof movement state changes, the interaction between the support and surrounding rock changes accordingly. The "support-surrounding rock" system is in a constantly dynamic state of mutual interaction.

\section{Mechanical analysis of movement law of support}

From the above analysis, it is seen that the support will move under the influence of roof movement. In the mining of a steeply dipping coal seam the support moves along the incline through subsidence, slip, and rotation and must be adjusted fundamentally or through coupling of the movement form to adapt to changes in external loads and constraints until it enters a new balanced state. Under the assumption that the floor is elastic foundation, a mechanical model of the motion of the support along the incline was established (Fig. 10).

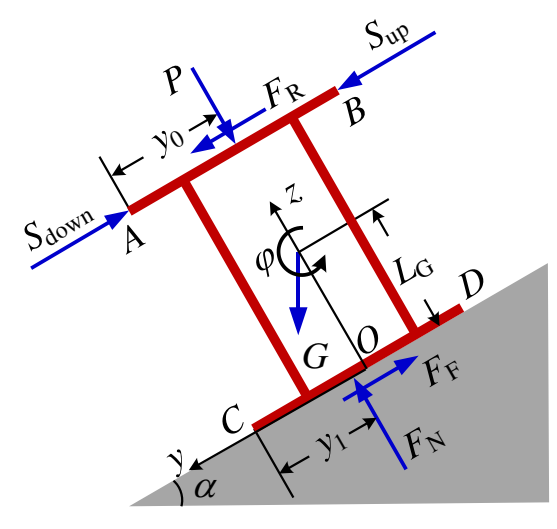

Fig.10 Mechanical model of motion of support along incline

In the figure, the $y$ - and z-axes are aligned downward along the incline and vertical coal seam, respectively, and the reverse rotation of the support is in the positive direction. The weight of the support $(G)$, the height of the center of gravity of the support $\left(L_{G}\right)$, normal load of the roof to the support, i.e., working resistance of the support $(P)$, and tangential load of the roof to the support, i.e., the friction between the support and the roof $\left(F_{R}\right)$, normal load of the floor 
to the support $\left(F_{N}\right)$, working loads between adjacent supports $\left(S_{u p}\right.$ and $\left.S_{\text {down }}\right)$, and tangential load of the floor to the support, i.e., the friction between the support and the floor $\left(F_{F}\right)$ are all given in $\mathrm{kN}$; the acting positions of the roof and floor loads ( $y_{0}$ and $y_{1}$, respectively) are given in meters and the rotational angle of the support $(\varphi)$ is given in degrees.

\subsection{Mechanical analysis of support sliding}

The sliding force $\mathrm{F}_{\mathrm{H}}$ of the support under loading by the roof can be expressed as

$F_{\mathrm{H}}=F_{\mathrm{R}}-\Delta S-G \sin (\alpha-\varphi)$

where $\Delta S=S_{\text {down }}-S_{\text {up }}$ is the interaction force between supports in $\mathrm{kN}$. When the sliding force $F_{H}$ is greater than the maximum static friction $F_{F m a x}$ between the support and the floor, the support slips. Here, we define the support sliding factor, $f$, as

$f=\frac{F_{H}}{F_{F \max }}$

When the absolute value of $f$ is greater than one, the supports slide. During the sliding process, the force $\Delta S$ gradually increases and the sliding force $F_{H}$ gradually decreases until the support reaches a new balanced state given by

$F_{R}-\Delta S-G \sin (\alpha-\varphi)+F_{F \max }=0$

\subsection{Mechanical analysis of support rotation}

When the acting load on the support changes, the resultant force couple on the support to deviate from zero and the support rotates. During this rotation, the load acting on the floor and the adjacent support is adjusted spontaneously and the resulting force couple gradually approaches zero until a new balanced state is reached. The rotational direction and amplitude are closely related to the load on the support, and the rotational dynamics can essentially be divided into non-lifting, upper-side lifting reverse, and lower-side lifting sequential rotation.

\subsubsection{Non-lifting rotation}

When the resultant force couple on the support is small, the support rotates without lifting away from the center point (point $O$ ) of its base. In this state, the force-couple balanced equation for the new balanced state is

$F_{N}\left(y_{1}-\frac{e}{2}\right)-\Delta S h+L_{G} G \sin (\alpha-\varphi)-F_{R} h+P\left(\frac{e}{2}-y_{0}\right)=0$

where $h$ and $e$ are the height and width, respectively, of the support in meters.

When the support rotates without lifting, the intensities of the forces contributing to the normal load applied by the floor to the support follow the "trapezoidal" distribution shown in Figs. 9 (a) and (b). According to the theory of elastic foundation, under this new balanced state the resultant force $F_{N}$ of the normal load of the floor and its acting position $y_{l}$ can be expressed as

$$
\begin{aligned}
& F_{\mathrm{N}}=-z_{\mathrm{O}} k_{0} d e \\
& \text { and } \\
& y_{1}=\frac{6 e z_{\mathrm{O}}-e^{2} \sin \varphi}{12 z_{\mathrm{O}}}
\end{aligned}
$$


respectively, where $z_{O}$ is the displacement of the center point of the support base in the $\mathrm{z}$ direction in the new balanced state in meters, $d$ is the length of the support base in meters, and $k_{0}$ is the foundation coefficient of the floor in $\mathrm{kNm}^{-3}$.

In this new balanced state, the loads $S_{\text {down }}$ and $S_{u p}$ between the adjacent supports can be expressed as

$S_{\text {down }}= \begin{cases}0 & y_{O}-\Delta y_{A} \geq 0 \\ -K_{S}\left(y_{O}-\Delta y_{A}\right) & y_{O}-\Delta y_{A}<0\end{cases}$

and

$S_{u p}= \begin{cases}0 & y_{O}-\Delta y_{B} \geq 0 \\ -K_{S}\left(y_{O}-\Delta y_{B}\right) & y_{O}-\Delta y_{B}<0\end{cases}$

respectively, where $K_{S}$ is the stiffness of the side guard jack in $\mathrm{kNm}^{-1}, y_{O}$ is the displacement of the midpoint of the support base along the y direction in new balanced state in meters, $\Delta y_{A}$ and $\Delta y_{B}$ are displacements caused by rotation of the upper and lower boundaries, respectively, of the canopy of the support along the incline direction in meters, which can be expressed as

$\Delta y_{A}=\Delta y_{B}=2 \sqrt{\frac{e^{2}}{4}+h^{2}} \sin \left(\frac{\varphi}{2}\right) \cos \left(\frac{\varphi}{2}+\arctan \frac{e}{2 h}\right)$

\subsubsection{Upper-side lifting reverse rotation}

When the total force couple to which the support is subjected is large and in a counterclockwise direction, the support rotates around the inclined lower boundary (point C) of its base, and the inclined upper boundary (point D) is lifted off. When the support reaches a new balanced state under this loaded and restrained state, the magnitude of the resultant force couple is equal to zero, i.e.

$$
F_{N} y_{1}-\Delta S h+G \sin (\alpha-\varphi) L_{G}-G \cos (\alpha-\varphi) \frac{e}{2}-F_{R} h-P y_{0}=0
$$

In this situation, the normal load on the floor is triangular, as shown in Fig. 9(c). According to the theory of elastic foundations, the resultant force $F_{N}$ of the normal load and its acting position $y_{l}$ can be expressed as

$$
F_{N}=\frac{z_{C}^{2} e k_{0}}{2 \sin \varphi}
$$

and

$y_{1}=\frac{-z_{C}}{3 \sin \varphi}$

respectively, where $z_{C}$ is the displacement in the $\mathrm{z}$ direction of the lower boundary of the support base in the new balanced state in meters. The acting loads $S_{\text {down }}$ and $S_{u p}$ between the adjacent supports can be expressed as

$S_{\text {down }}= \begin{cases}0 & y_{C}-\Delta y_{A} \geq 0 \\ -K_{S}\left(y_{C}-\Delta y_{A}\right) & y_{C}-\Delta y_{A}<0\end{cases}$

and

$S_{u p}= \begin{cases}0 & y_{C}-\Delta y_{B} \leq 0 \\ -K_{S}\left(y_{C}-\Delta y_{B}\right) & y_{C}-\Delta y_{B}>0\end{cases}$

respectively, where $y_{C}$ is the displacement in the y direction of the lower boundary of the support base in the new 
balanced state in meters, and $\Delta y_{A}$ and $\Delta y_{B}$ can be expressed as

$\Delta y_{A}=h \sin \varphi$

and

$\Delta y_{B}=2 \sqrt{e^{2}+h^{2}} \sin \left(\frac{\varphi}{2}\right) \sin \left(\frac{\varphi}{2}+\arctan \frac{h}{e}\right)$

respectively.

\subsubsection{Lower-side lifting sequential rotation}

When the total force couple to which the support is subjected is large and in a clockwise direction, the support rotates around the inclined upper boundary (point D) of its base and the inclined lower boundary (point C) of the base is lifted off. When the support reaches a new balanced state under this loaded and restrained state, the total force and resultant force couple of the support in the $\mathrm{z}$ direction are zero, that is:

$-F_{N}\left(e-y_{1}\right)-\Delta S h+G \sin (\alpha-\varphi) L_{G}-G \cos (\alpha-\varphi) \frac{e}{2}-F_{R} h-P\left(e-y_{0}\right)=0$

In this situation, the normal load of the floor to the support is triangular, as shown in Fig. 9 (d). According to the theory of elastic foundations, the resultant force $F_{N}$ of the normal load and its acting position $y_{l}$ can be expressed as

$F_{N}=\frac{-z_{D}^{2} c k_{0}}{2 \sin \varphi}$

and

$y_{1}=e-\frac{z_{D}}{3 \sin \varphi}$

respectively, where $z_{D}$ is the displacement in the $\mathrm{z}$ direction of the lower boundary of the support base in the new balanced state in meters. In this new balanced state, the acting loads $S_{\text {down }}$ and $S_{u p}$ between the adjacent supports can be expressed as

$S_{\text {down }}= \begin{cases}0 & y_{D}+\Delta y_{A} \geq 0 \\ -K_{S}\left(y_{D}+\Delta y_{A}\right) & y_{D}+\Delta y_{A}<0\end{cases}$

and

$S_{u p}= \begin{cases}0 & y_{D}+\Delta y_{B} \leq 0 \\ -K_{S}\left(y_{D}+\Delta y_{B}\right) & y_{D}+\Delta y_{B}>0\end{cases}$

respectively, where $y_{D}$ is the displacement in the y direction of the upper boundary of the support base in the new balanced state in meters. In the new balanced state, $\Delta y_{A}$ and $\Delta y_{B}$ can be expressed as

$\Delta y_{A}=-2 \sqrt{e^{2}+h^{2}} \sin \left(\frac{\varphi}{2}\right) \sin \left(\frac{\varphi}{2}+\arctan \frac{h}{e}\right)$

and

$\Delta y_{B}=-h \sin \varphi$ 
respectively.

\subsection{Mechanical analysis of support subsidence}

As the working resistance of the support increases, the support sinks further. During the rotation and subsidence of the support, the resultant force and force couple of the support along the $\mathrm{z}$ direction gradually approach zero until a new balanced state is reached:

$$
F_{N}-P-G \cos (\alpha-\varphi)=0
$$

\section{Case study}

In the following case, the influence of roof load and mining height on the stability of the support is analyzed based on data obtained from working face 25221 of coalmine 2130(Xinjiang Coking Coal Group Ewirgol). The value of basic parameters used in the model analysis are listed in Table 2.

Table 2 Physical parameters used in the model

\begin{tabular}{ccc}
\hline Parameter & name & value \\
\hline$a$ & Width of support & $1.6 \mathrm{~m}$ \\
$h_{0}$ & Length of support base & $3 \mathrm{~m}$ \\
$G$ & Height of support center of gravity & $b / 2 \mathrm{~m}$ \\
$k_{0}$ & Weight of support & $15 \times 9.8 \mathrm{kN}$ \\
$P$ & Foundation coefficient of floor & $1.0 \times 10^{5} \mathrm{kN} / \mathrm{m}^{3}$ \\
$\mu_{1}$ & Setting load of support & $5,000 \mathrm{kN}$ \\
$\mu_{2}$ & Coefficient of friction between support and roof & 0.3 \\
\hline
\end{tabular}

\subsection{Influence of roof load on stability of support}

Figures 11-13 show the influence of the load on the stability of the support at a mining height of $4 \mathrm{~m}$. It is seen from the figure that changing the acting load of the roof on the support alters the moving state of the support, with the magnitude, direction, and action point of the roof load affecting the stability of the support to different degrees.

When the load on the roof is not eccentric and the support is not subjected to a tangential load (i.e., $y_{0}=e / 2 \mathrm{~m}, F_{R}$ $=0 \mathrm{kN}$ ), the main force inducing sliding and rotation of the support is the component of gravity parallel to the incline. As the working resistance, $P$, increases, the support sinks further and the amount of subsidence $z_{A}$ of the lower boundary of the support increases. However, the main force couple formed by the incline-parallel component of gravity, rotation angle $\varphi$, and the force $\Delta S$ remain unchanged as $P$ increases and, because the main force couple is small, $\varphi$ and $\Delta S$ are also small. Similarly, the sliding force $F_{H}$ remains unchanged even as the maximum static friction $F_{F m a x}$ between the support and floor gradually increases. As a result, the sliding factor $f$ gradually decreases to a value much lower than one, which means that the support will not slide down or rotate without lifting from the original position, as shown in Fig 11 . 

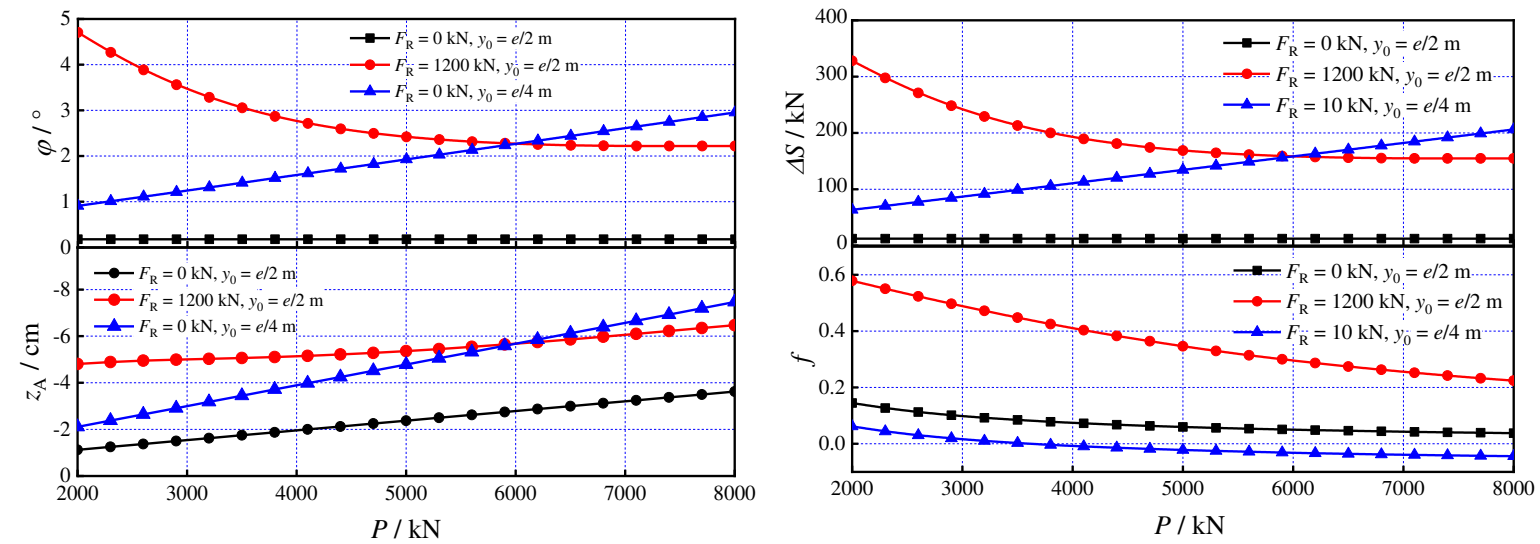

(a) Influence of working resistance on support rotation;(b) Influence of working resistance on support sliding

Fig.11 Influence of working resistance on support stability $(h=4 \mathrm{~m})$

If the roof load is not eccentric and the support is subjected to a tangential load, the main forces that induce support sliding and rotation include the component of gravity on the support and the tangential load, $F_{R}$. As $F_{R}$ is increased, the sliding force on the support, main force couple formed by the tangential load, rotation angle $\varphi$ of the support, acting force $\Delta S$ between the supports, and amount of subsidence $z_{A}$ at the lower boundary of the support base all gradually increase, while the sliding factor $f$ of the support gradually decreases. As the tangential load of the roof evolves from $F_{R}$ to $-F_{R}$, the mode of support motion evolves from upper-side lifting with reversed rotation to lower-side lifting with sequential rotation, as shown in Fig 12. If the roof load is not eccentric and the support is subjected to a tangential load $\left(y_{0}=e / 2 \mathrm{~m}, F_{R}=1,200 \mathrm{kN}\right)$, the working resistance can be increased to effectively enhance the stability of the support. By increasing the working resistance, the maximum static friction $F_{F \max }$ can be increased, reducing the sliding factor $f$ and the probability of support sliding, and the rotational force couple formed by the tangential load of the roof can be reduced, in turn reducing the rotational amplitude and the force between the supports.
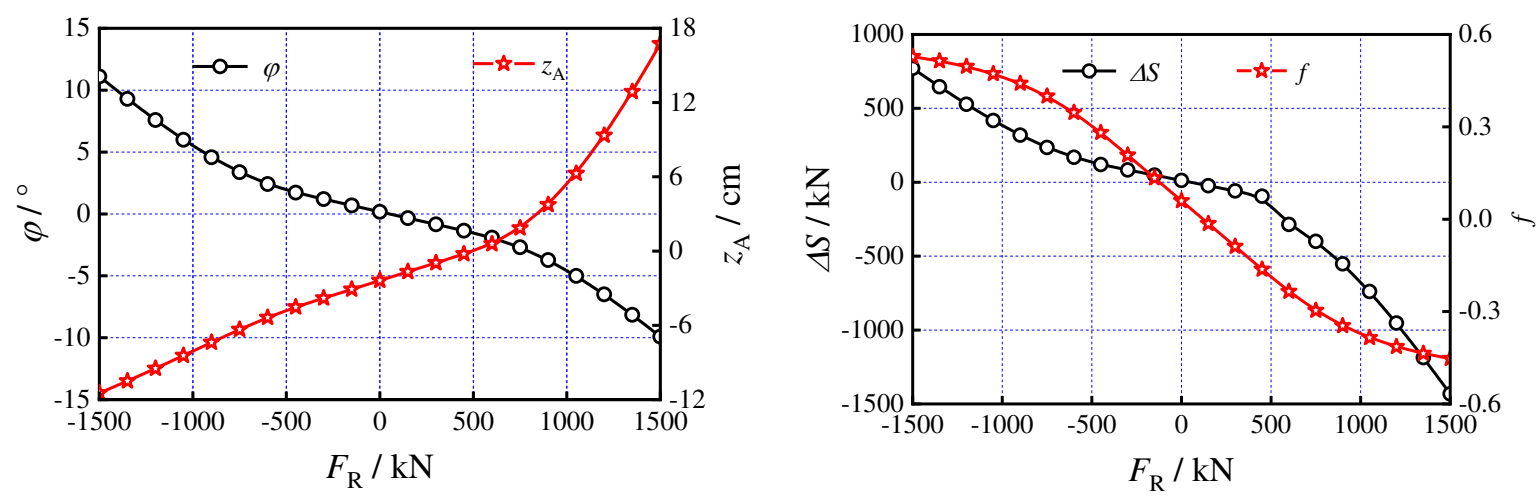

(a) Influence of tangential load on support rotation;(b) Influence of tangential load on support sliding

\section{Fig.12 Influence of tangential load of roof on support stability $(h=4 \mathbf{m})$}

If the support is not subjected to a tangential load from the roof and the load is eccentric, the main forces inducing support sliding and rotation are gravity and the normal load, respectively. As the degree of load eccentricity is increased, the main force couple formed by the working resistance, rotation angle $\varphi$, force between supports $\Delta S$, and value of subsidence $z_{A}$ of the lower boundary all gradually increase. At the same time, the component of gravity along the incline of the support remains unchanged, while the support sliding factor $\mathrm{f}$ increases with the increase in $\Delta S$. As the action position of the load $y_{0}$ evolves from zero to $e$, the support dynamics change from upper-side lifting with reverse rotation to non-lifting rotation and finally to lower-side lifting with sequential rotation, as shown in Fig 13. It is seen from Fig. 11 that, when the support is eccentrically loaded but not subject to the tangential load of the roof $\left(y_{0}=e / 4 \mathrm{~m}, F_{R}=0\right.$ $\mathrm{kN}$ ), the enhancement of the working resistance increases the probability of support instability; however, even though the maximum static friction $F_{F m a x}$ increases, the probability of support sliding is reduced as the working resistance on the support increases. 

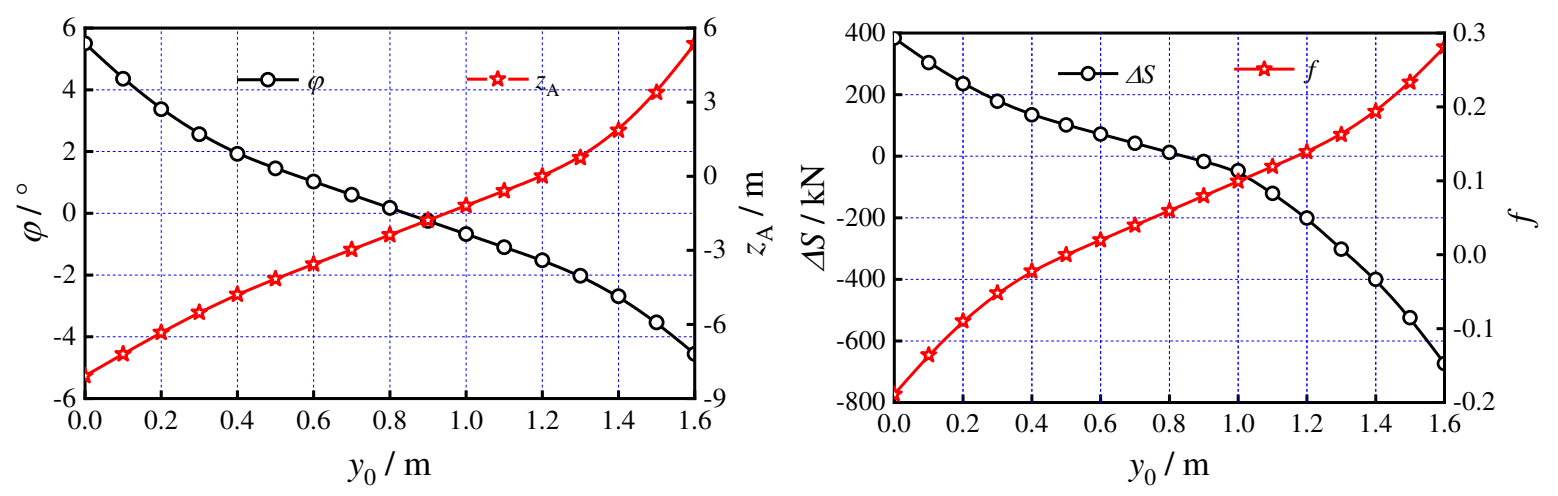

(a) Influence of action position on support rotation;(b) Influence of action position on support sliding

Fig.13 Influence of action position of normal loading on support stability $(h=4 \mathbf{m})$

\subsection{Influence of mining height on support stability}

Fig 14 shows the influence of mining height on the stability of the support at a support working resistance of 5,000 $\mathrm{kN}$. The following observations are made from the figure:

(1) If the support is not eccentrically loaded and not subject to the tangential load of the roof $\left(y_{0}=e / 2 \mathrm{~m}, F_{R}=0\right.$ $\mathrm{kN}$ ), the main force causing rotation and sliding is the component of gravity along the incline. As the mining height increases, the height of the center of gravity, main force couple formed by the component of gravity along the incline, rotational angle $\varphi$, inter-support force $\Delta S$, and displacement of the lower boundary of the base all increase. At the same time, the increase in the force $\Delta S$ induced by increasing the mining height reduces both the sliding force and factor on the support.

(2) If the support is not eccentrically loaded and subject to the tangential load of the roof ( $y_{0}=e / 2 \mathrm{~m}, F_{R}=1,200$ $\mathrm{kN}$ ), the component of gravity along the incline and the tangential load of the roof are the primary causes of rotation and sliding of the support. As the mining height increases, the force couple formed by the tangential load, component of gravity along the incline, rotation angle $\varphi$, inter-support force $\Delta S$, and displacement of the lower boundary of the base all increase, while the increase in $\Delta S$ induced by increasing the mining height reduces the sliding force and factor on the support.

(3) If the support is eccentrically loaded and not subject to the tangential load of the roof $\left(y_{0}=e / 4 \mathrm{~m}, F_{R}=0 \mathrm{kN}\right)$, the primary force causing sliding is the component of gravity along the incline while the primary forces causing rotation are the component of gravity along the incline and the tangential load. As the mining height increases, the height of the center of gravity, inter-support force $\Delta S$, and anti-rotational force couple formed by $\Delta S$ increase, while the rotational angle and the amount of lower boundary subsidence of the base decrease. At the same time, the enhancement of $\Delta S$ results in decreases in the sliding force and factor.
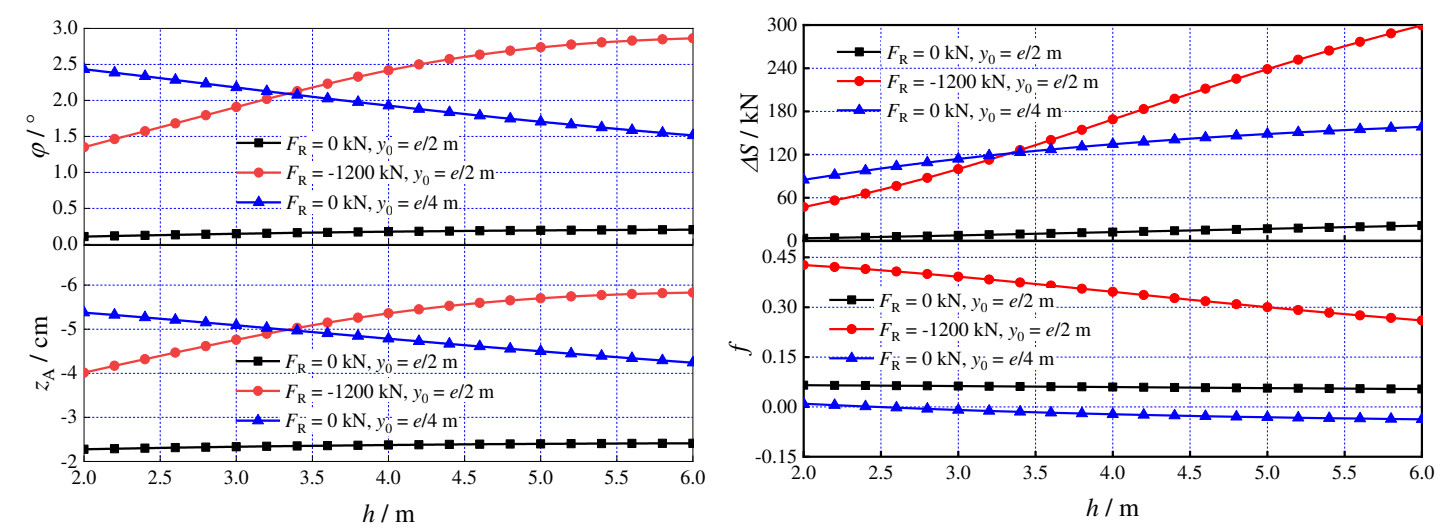

(a) Influence of mining height on support rotation;(b) Influence of mining height on support sliding 
Fig.14 Influence of mining height on support stability $(P=5,000 \mathrm{kN})$

From the above analysis, it is seen that, in the mining of steeply dipping coal seams, the support will move with the roof and that the magnitude and direction of force, action point, and mining height will affect the stability of the support to various extents. The tangential load and action position of the roof load have the most significant impact on the stability of the support and can affect both the amplitude and direction of motion of the support. Roof loading inevitably leads to rotation and subsidence of the support, with the force $\Delta S$ and the sliding force gradually increasing with the amplitudes of rotation and subsidence.

Combining with the law of surrounding rock migration in longwall mining of steeply dipping coal seams, it can be concluded that focusing on the characteristics of uneven filling of the gob in the middle and upper areas of the working face or the long distance of the filling gangue from the working face, large roof movement amplitude, poor roof structure stability, support loading and variable behavior, etc. The stability control of the support should start with the optimization of the support structure and the mining process. In terms of support structure, the support is required to have independent base adjustment frame, side pushing device, reinforced side guard, and base lifting device. In particular, in the upper area of the working face, multiple supports should be connected by an oil cylinder to form an integral anti-skip unit to improve the overall stability of support in the range. In terms of the optimization of the mining process, the main aim is to move the support, and the operation should be strictly in accordance with the working face mining process regulations. The "down-up" moving sequence of "sliding advance of support" and the combination of the whole and the part should be adopted to ensure that the stability of the support during the dropping and moving process is controlled. These laws of surrounding rock migration under the longwall mining of steeply dipping coal seams clarify the need for full-time pressure monitoring of the working face, with the key goal of obtaining early warning based on characteristics such as empty gob filling in the upper and middle areas of the wall, increased distance between the gangue and the working face, large motion amplitudes, poor roof structure stability, or variable behavior of the support. In the event of a sudden increase in load or poor positioning, immediate measures should be taken to protect the roof and floor and adjust the support position.

\section{Conclusion}

The key to safe and efficient longwall mining in steeply dipping coal seams is the effective control of surrounding rock by undertaking the challenging task of controlling the stability of the "support-surrounding rock" system. With the goal of reducing challenges to managing support stability in the longwall mining of steeply dipping coal seams, this study assessed the characteristics of non-uniform filling in the gob, the interactions within the "support-surrounding rock" system in different areas along the incline, and the motion laws governing the support. The following findings were made:

(1) It was found that the filling characteristics of the gob have obvious asymmetries along the incline and anisotropies along the strike. Depending on the angle of the coal seam, the gangue will roll (slide) downward along the incline. In the deep gob, a non-uniform filling zone with lower, middle, and upper areas of compaction, filling, and hanging, respectively, is formed. In the middle and upper areas, an inverted triangular hollow face is formed on the floor behind the support. As the angle of the coal seam, length of the working face, and mining height increase, these characteristics of non-uniform filled-in gob formation are enhanced.

(2) In the lower area of the working face, the gob is in a high-density filled-in state with limited space for surrounding rock migration and a relatively stable "support-surrounding rock" system. There is a complex interaction between the "support-surrounding rock" system in the upper and middle areas of the working face, in which the amplitude of roof movement is large and the stability of the surrounding rock structure is poor. There are obvious phenomena of eccentric loading and no-loading of the supports and biting between supports, and it is difficult to control support stability. Under the influence of the movement of the roof, the supports will also move.

(3) The magnitude and direction of force on the support, action point, and mining height will affect support stability 
to different extents. The tangential load and acting position of the roof load affect the amplitude and direction of motion of the support, with a more significant impact on the stability of the support than other factors. Under roof loading, the support will inevitably rotate and subside with a gradually increasing amplitude that leads to a gradual increase in the inter-support and sliding forces.

\section{Acknowledgment}

The background data of the 25221 working face and the on-site monitoring equipment and technologies were provided by the 2130 Coal Mine. The physical similarity simulation experiment was provided by the Key Laboratory of Western Mine Exploitation and Hazard Prevention and the State Key Laboratory of Coal Resources in Western China.

\section{Author Contributions}

L.S. provided the general idea of the paper. W. T. wrote the article, and W. Y. had a comprehensive grasp of the article. H.F and W. T. completed simulation experiments on similar materials. Z.H. provided the convenience of on-site monitoring. All authors have read and agreed with the published version of the manuscript.

\section{Funding}

This work was supported by the National Natural Science Foundation of the PRC (51974227, 51634007) and Major Scientific and Technological Innovation Projects in Shandong Province (2019JZZY020326).

\section{Compliance with Ethical Standards \\ Conflict of Interest}

The authors declare that they have no conflict of interest.

\section{Code availability}

Not applicable.

\section{References:}

[1].Yongping W, Dongfeng Y, and Panshi X. Theory and Technology of Fully Mechanized Longwall Mining in steeply dipping Coal Seams[M].Science Press, Beijing, 2017 [In Chinese].

[2].Yongping W, Bosheng H, and Ding L, Risk assessment approach for rockfall hazards in steeply dipping coal seams. International Journal of Rock Mechanics and Mining Sciences, 138:104626. https://doi.org/10.1016/j.ijrmms.2021.104626.

[3].Jin-an W, Jun-ling J, Criteria of support stability in mining of steeply inclined thick coal seam. International Journal of Rock Mechanics and Mining Sciences. 82(2016), pp.22-35. https://doi.org/10.1016/j.ijrmms.2015.11.008

[4]. Frumkin R.A. Predicting rock behaviour in steep seam faces. International Journal of Rock Mechanics and Mining Sciences \& Geomechanics Abstracts,20(1983), pp. A12-A13. (in Russian) https://doi.org/10.1016/01489062(83)91717-5

[5]. Ladenko, A. Improvements in working steep seams. International Journal of Rock Mechanics and Mining Sciences \& Geomechanics Abstracts, 11(1974), pp.247-. https://doi.org/10.1016/0148-9062(74)92108-1

[6].Kulakov, V. N. Geomechanical conditions of mining steep coal beds, Journal of Mining Science,7 (1995), pp. 136143.

[7].Aksenov, V. V, Lukashev, G. E. Design of universal equipment set for working steep seams, Ugol,4(1993), pp. 5-9.

[8].Proyavkin, E. T. New nontraditional technology of working thin and steep coal seams. Ugol Ukrainy, 3 (1993), pp. $2-4$.

[9].S.S. Peng. Longwall Mining, Department of Mining Engineering West Virginia University, 2006.

[10].Yongping W, Panshi X, and Dongfeng Y, Theory and practice of fully mechanized longwall mining in steeply dipping coal seams. Mining Engineering, 65(2013), pp.35-41.

[11].Shenghu L, Yongping W, and Panshi X, Mechanical analysis of support stability in longwall mining of steeply dipping seam. Journal of China Coal Society, 44 (2019), pp.2664-2672 [In Chinese].

[12].Hongwei W, Yongping W, and Ming L, Roof-breaking mechanism and stress-evolution characteristics in partial backfill mining of steeply inclined seams. Geomatics, Natural Hazards and Risk. 11(2020), pp.2006-2035. https://doi.org/10.1080/19475705.2020.1823491 
[13].Shenghu L, Yongping W, and Panshi X, Load and instability characteristics of support in large mining height fullymechanized face in steeply dipping seam. Journal of China Coal Society, 43(2018), pp.3320-3328 [In Chinese].

[14].Xingping L, Hui S, and Pengfei S, Structure instability forecasting and analysis of giant rock pillars in steeply dipping thick coal seams. International Journal of Minerals, Metallurgy and Materials. 22(2015), pp.1233-1244. https://doi.org/10.1007/s12613-015-1190-z

[15].Panshi X, Yi L, and Yongping W, Roof Deformation Associated with Mining of Two Panels in Steeply Dipping Coal Seam Using Subsurface Subsidence Prediction Model and Physical Simulation Experiment. Mining, Metallurgy and Exploration. 37(2020), pp.581-591. https://doi.org/10.1007/s42461-019-00156-X

[16].Shenghu L, Yongping W, and Kongzhi L, Asymmetric load and instability characteristics of coal wall at large mining height fully mechanized face in steeply dipping seam. Journal of China Coal Society ,43(2018), pp.18291836 [In Chinese].

[17].Yi L, An improved influence function method for predicting subsidence caused by longwall mining operations in inclined coal seams. International Journal of Coal Science \& Technology, 2(2015), pp.163-169.

[18]. Basarir H, Ferid Oge I, and Aydin O, Prediction of the stresses around main and tail gates during top coal caving by 3D numerical analysis. Int $\mathrm{D}$ Rock Mech Min Sci,76(2015), pp.88-97. https://doi.org/10.1016/j.ijrmms.2015.03.001

[19].Islavath SR, Deb D, and Kumar H, Numerical analysis of a longwall mining cycle and development of a composite longwall index. Int J Rock Mech Min Sci,89(2016), pp.43-54.

[20].Jiachen W, Weijie W, Jinwang Z, Stability analysis of support around the longwall top-coal caving mining in steeply thick coal seam. Journal of China Coal Society, 42(2017), pp.2783-2791 [In Chinese].

[21]. Singh GSP, Singh UK. Prediction of caving behavior of strata and optimum rating of hydraulic powered support for longwall workings. Int J Rock Mech Min Sci,47(2010), pp.1-16.

[22]. Prusek S, Rajwa S, Wrana A, Krzemień A, Assessment of roof fall risk in longwall coal mines. International Journal of Mining, Reclamation and Environment . 31(2017), pp.558-574. http://dx.doi.org/10.1080/17480930.2016.1200897

[23].Bingxiang H, Youzhuang W, and Shenggen C, Cavability control by hydraulic fracturing for top coal caving in hard thick coal seams. Int J Rock Mech Min,74(2015), pp.45-57.

[24].Dongfeng Y, Zhu L, and Wendong C, Study on loading monitoring of side guard plate powered support of fullymechanized top coal caving mining in high inclined thick seam.Coal Science and Technology, 44(2016), pp.145149. 

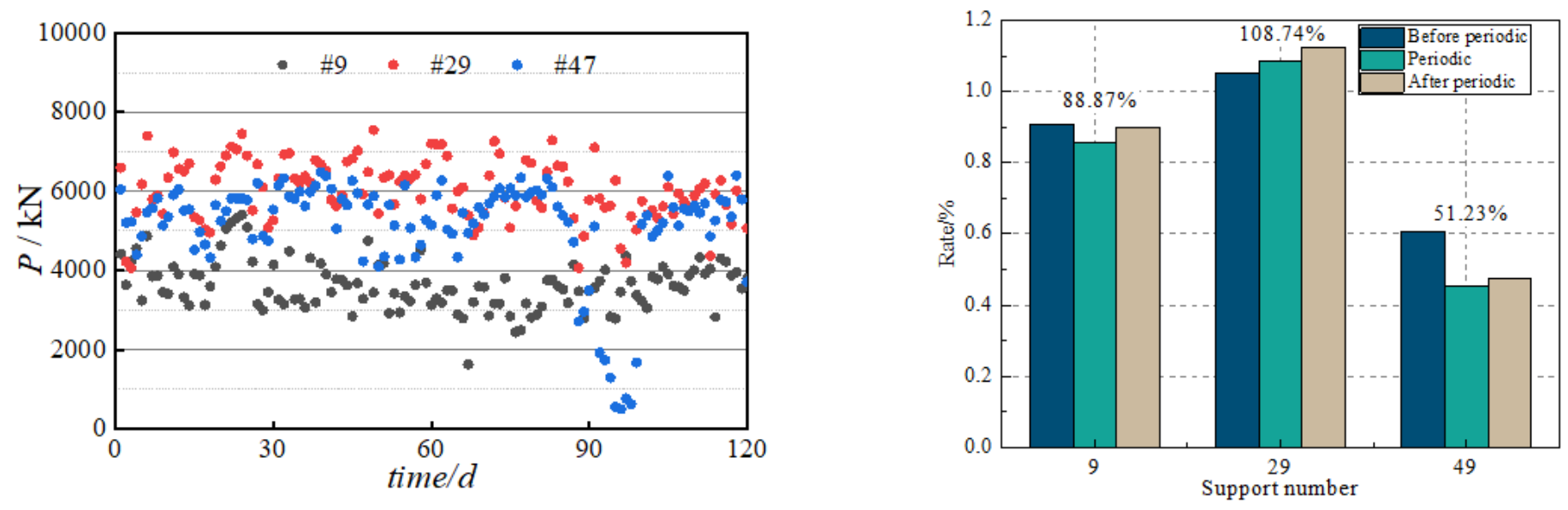

(a) support resistance; (b)load ratio of back to front leg

Figure 1

Support resistance and load ratio of back to front leg in different areas
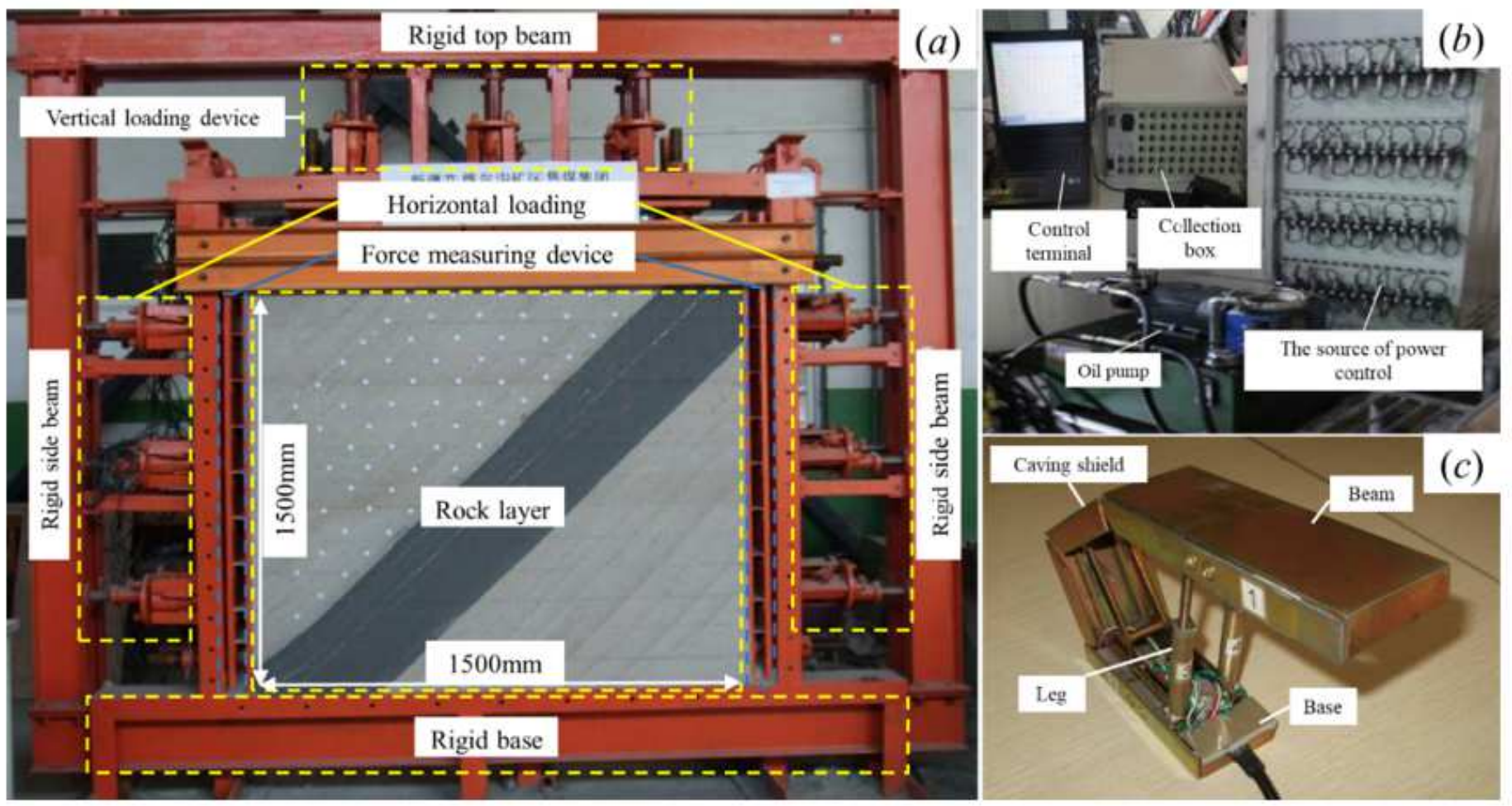

(a) Model; (b) Date collection system; (c) Support model

\section{Figure 2}

Test model 


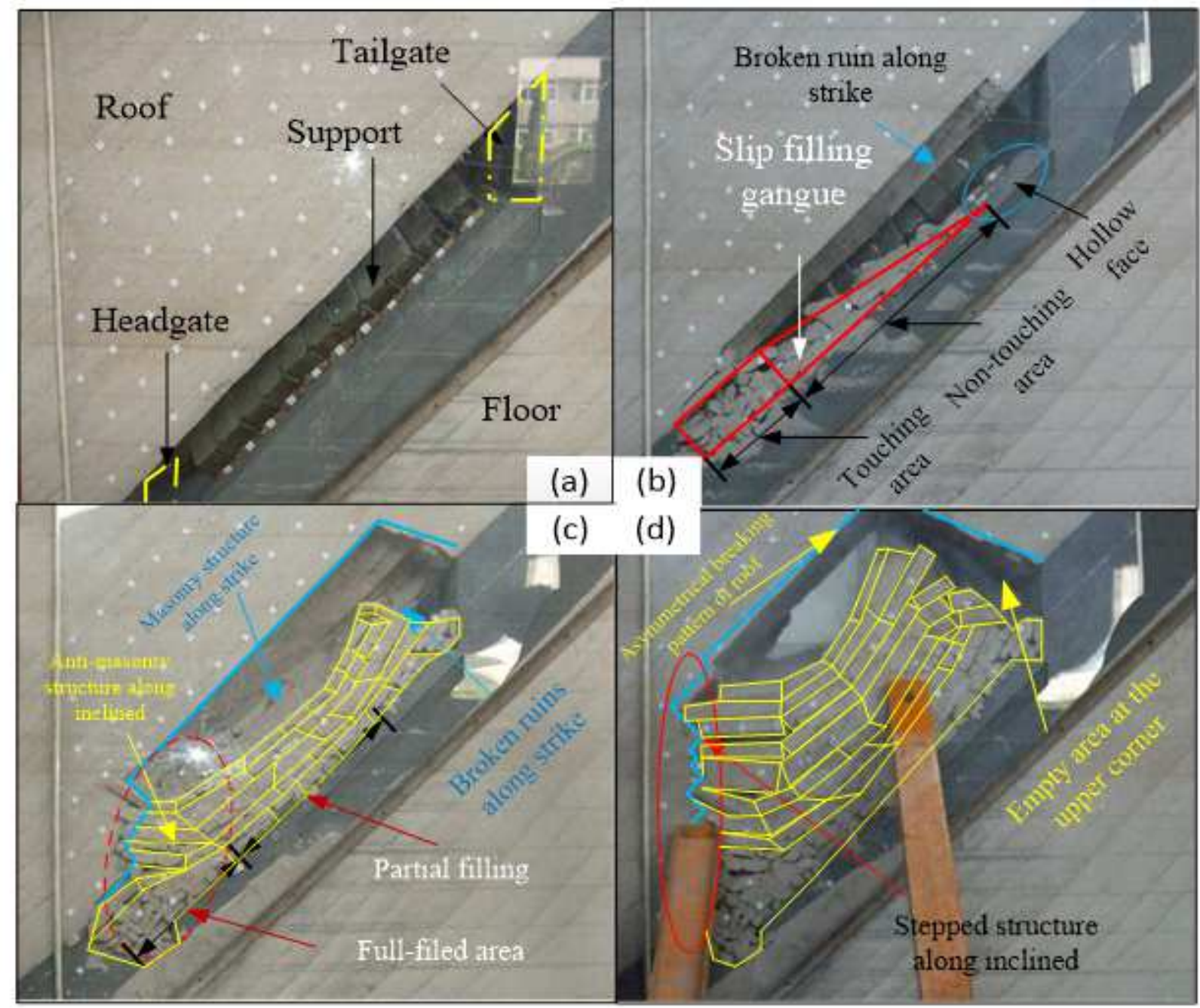

Figure 3

Characteristics of caving and filling of floor 


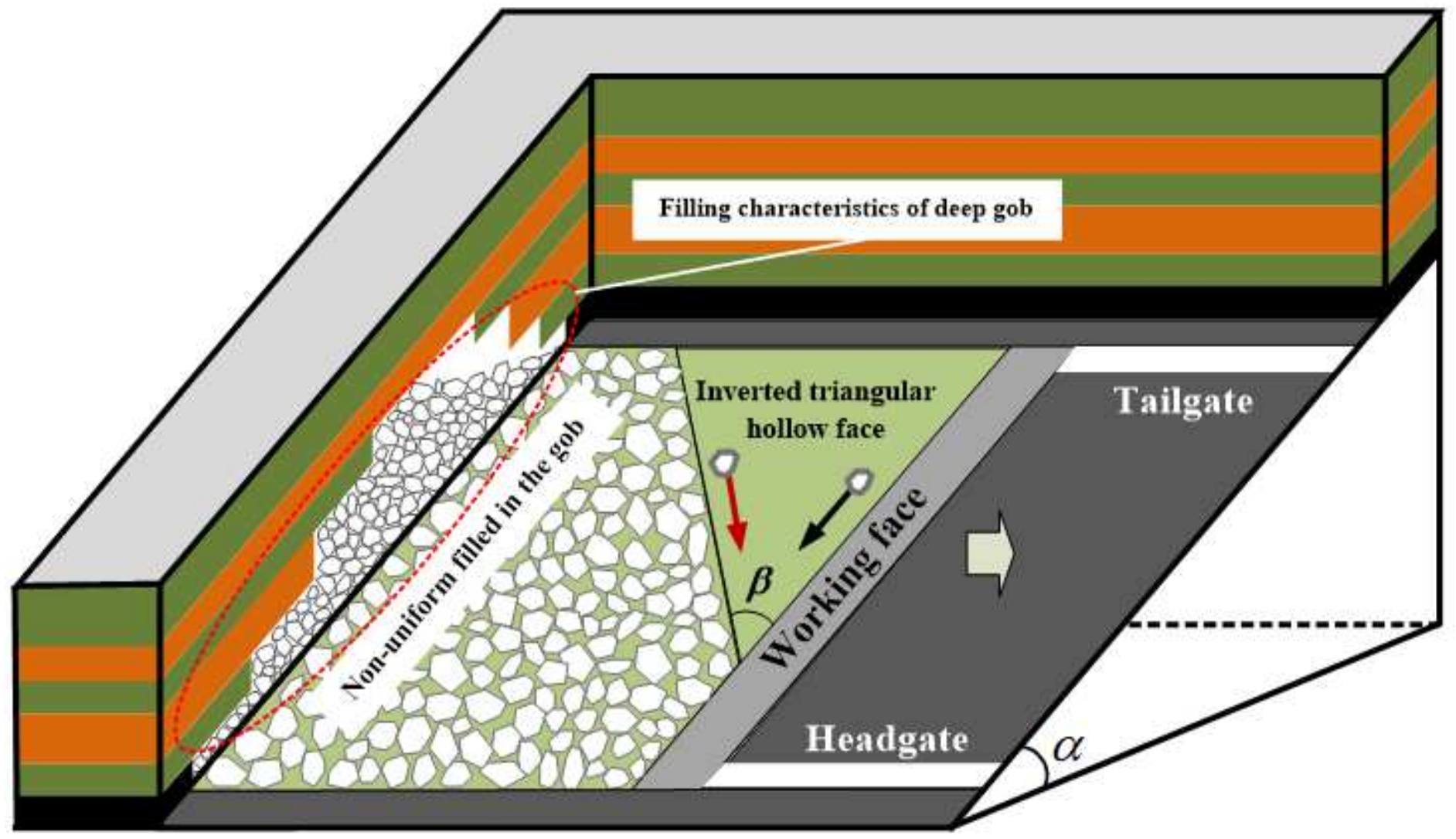

Figure 4

Filling characteristics of the gob 


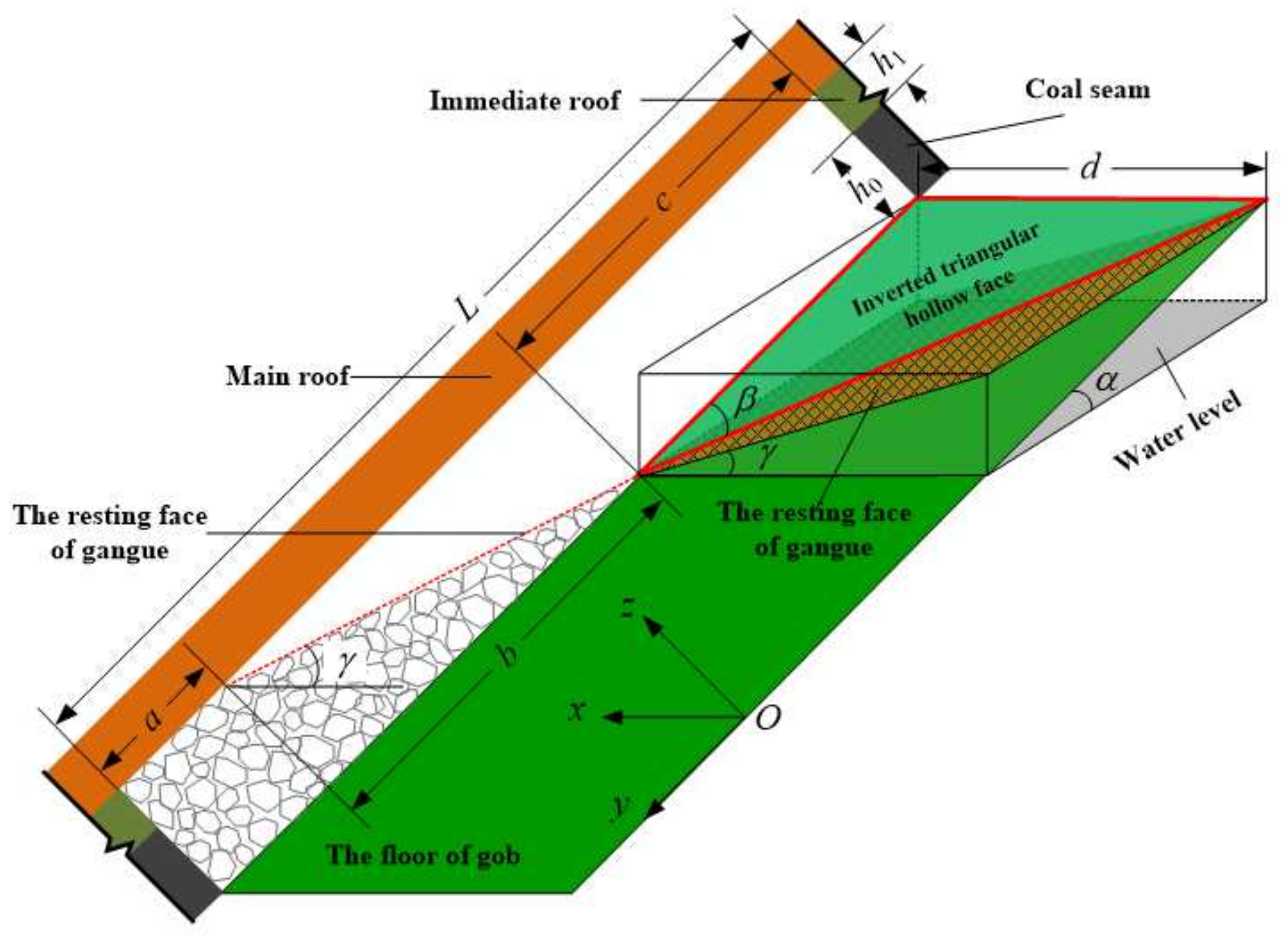

Figure 5

Schematic of gob-filling characteristics
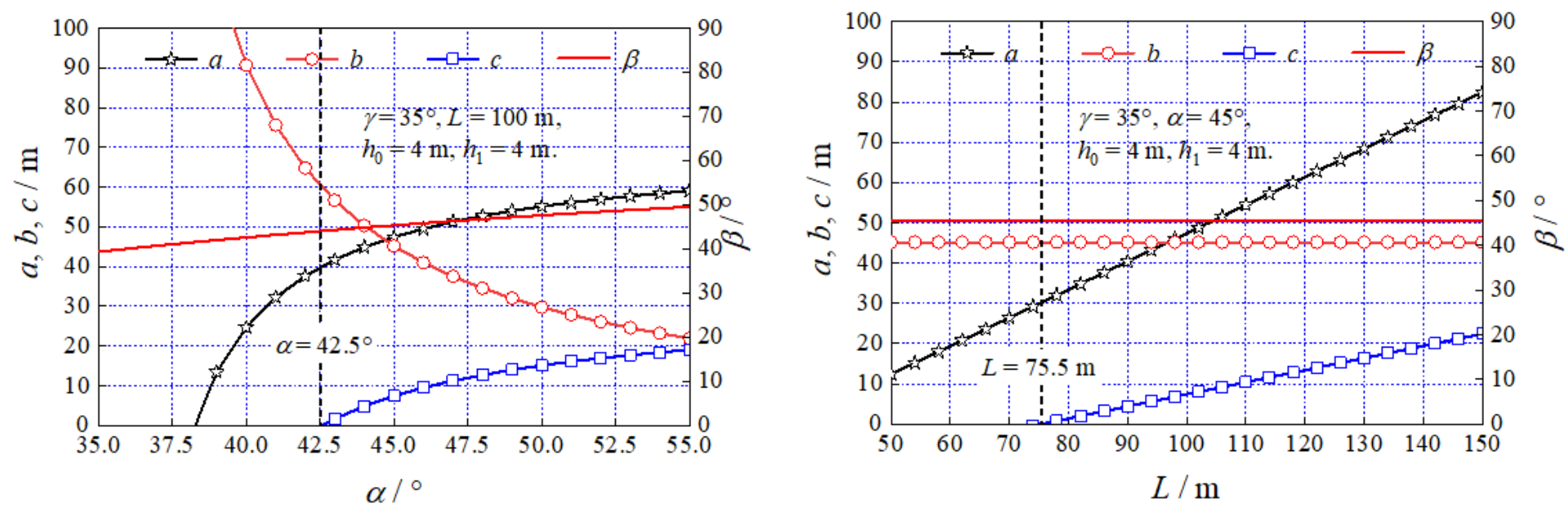

(a) Influence of angle $\alpha$ on filling characteristics; (b) Influence of length L on filling characteristics 

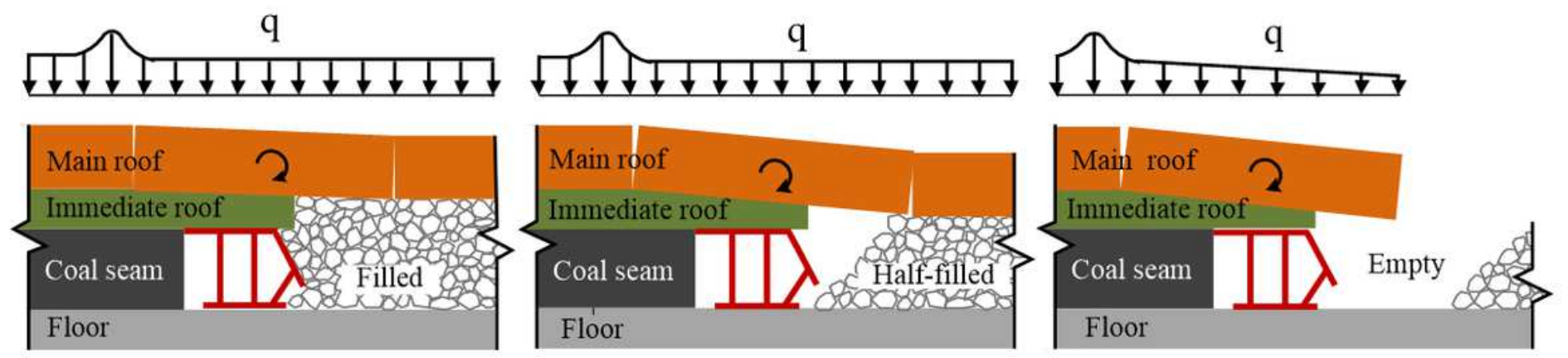

(a) Lower area of inclination;(b) middle area of inclination;(c) upper area of inclination

\section{Figure 7}

Interaction relationship of "support-surrounding rock" system along the strike

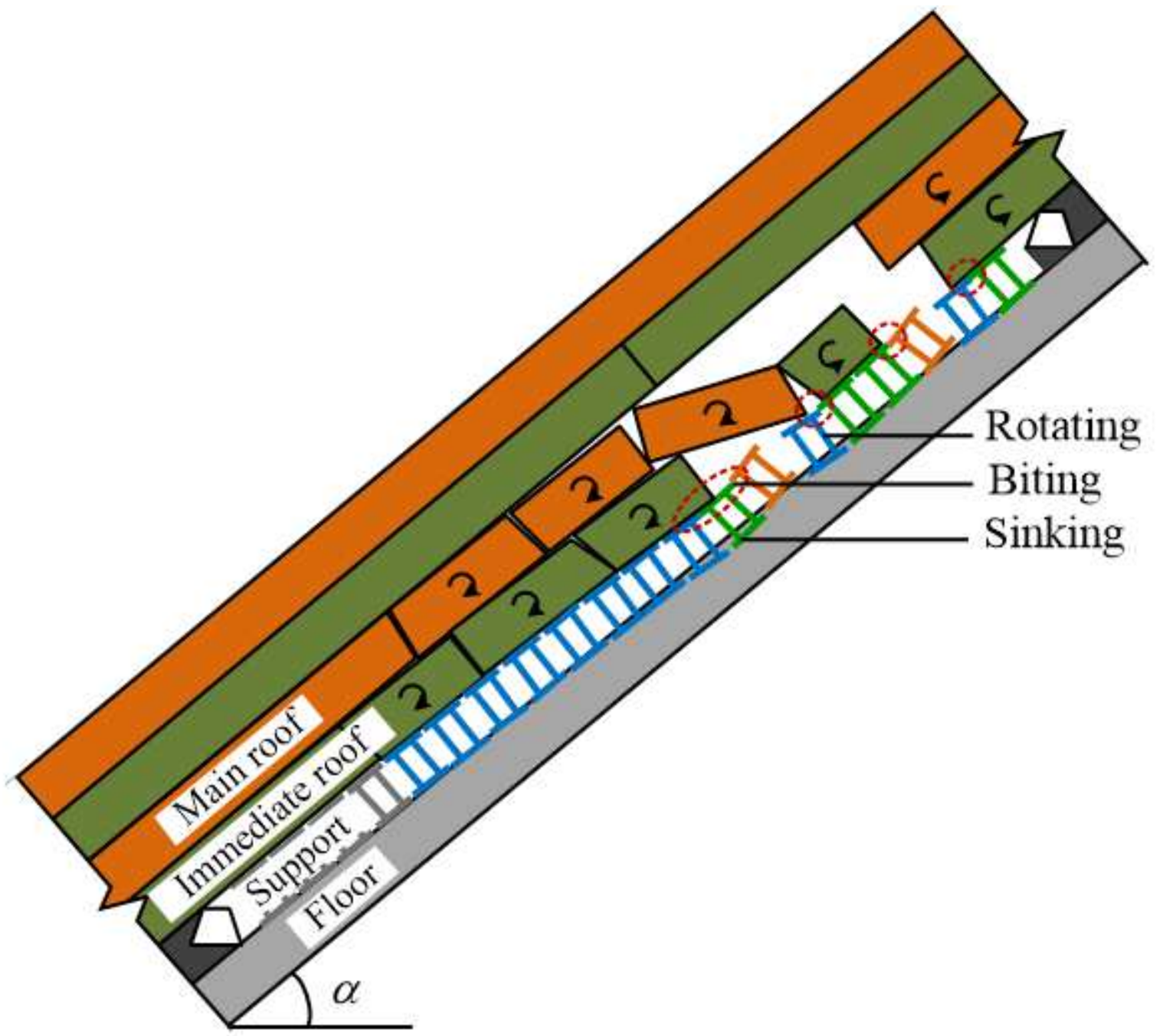

Figure 8

Interaction relationship of "support-surrounding rock" system along the inclined 

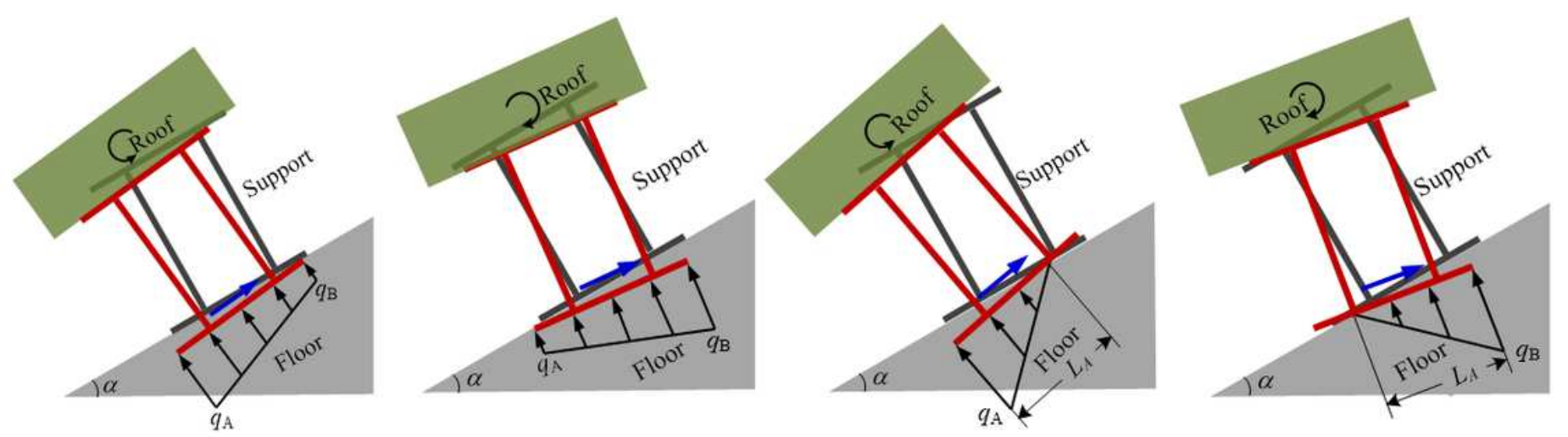

(a) Subsidence + reverse rotation ;(b) Subsidence + forward rotation; (c) Subsidence + reverse rotation + lift off ; (d) Subsidence + forward rotation + lift off

Figure 9

Interaction between the support and surrounding rock

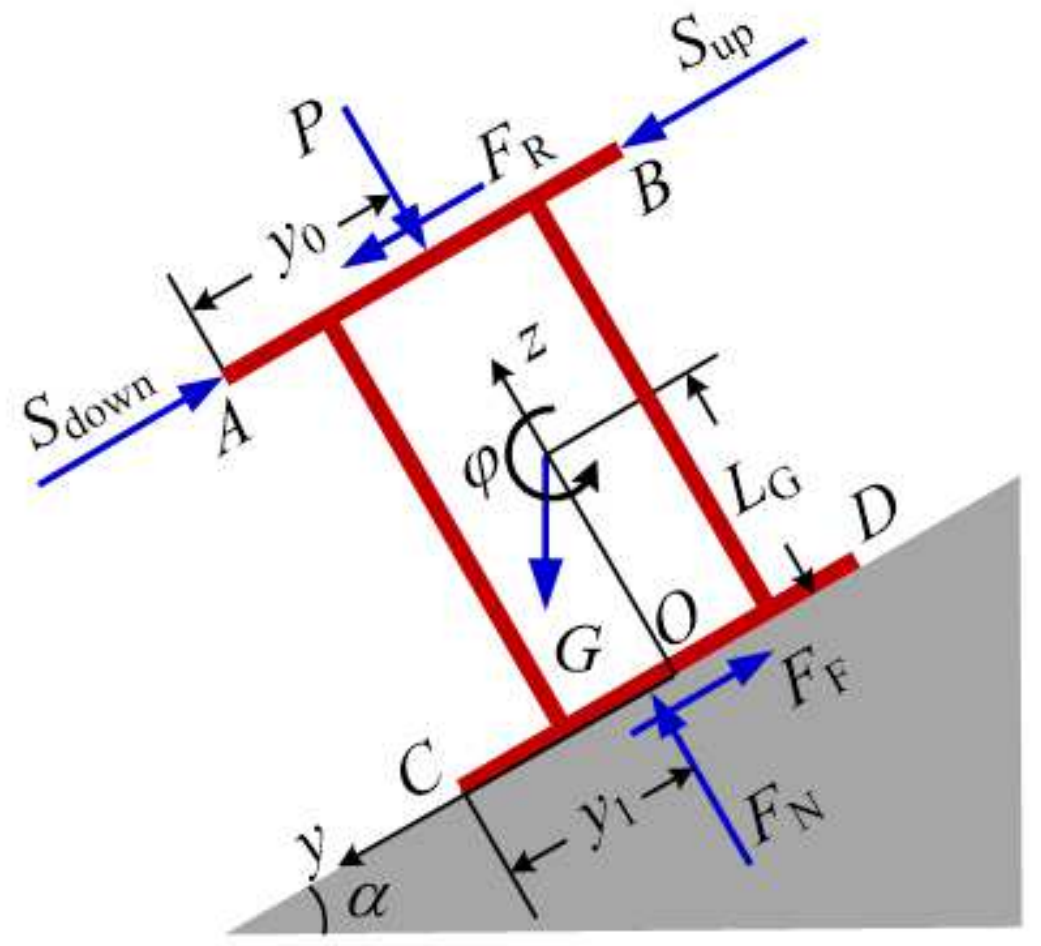

Figure 10

Mechanical model of motion of support along incline 

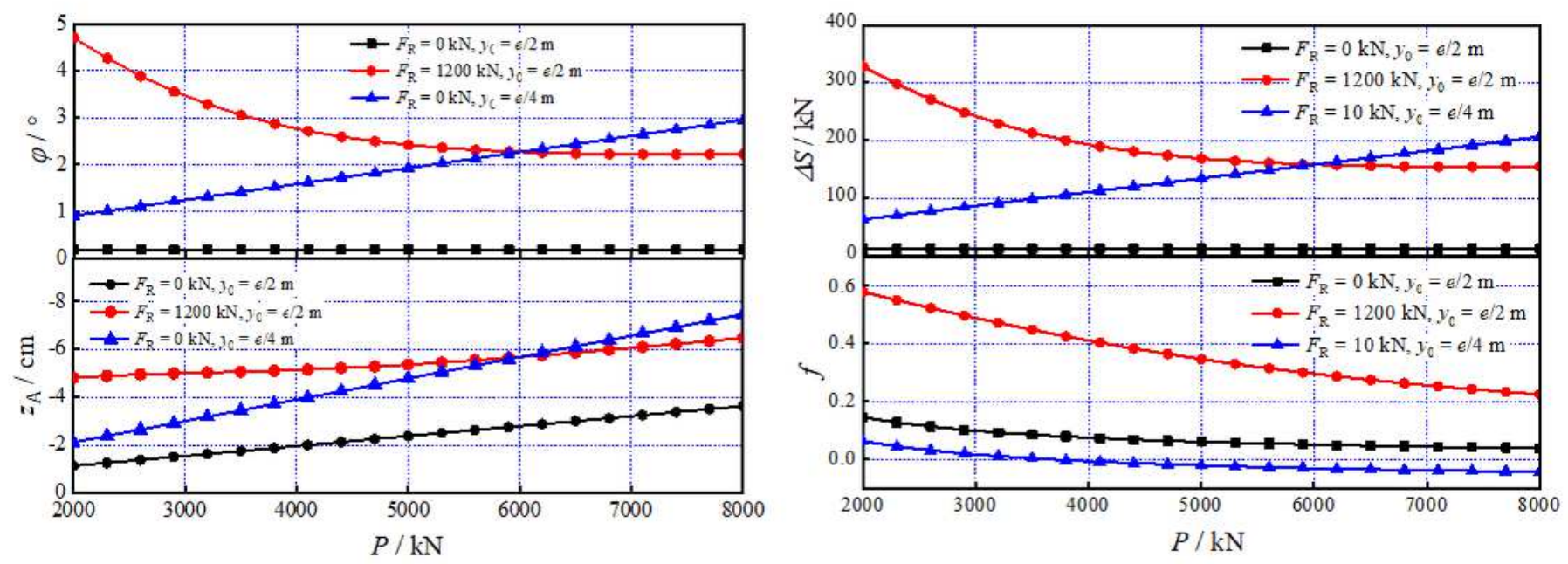

(a) Influence of working resistance on support rotation;(b) Influence of working resistance on support sliding

\section{Figure 11}

Influence of working resistance on support stability (h=4 m)
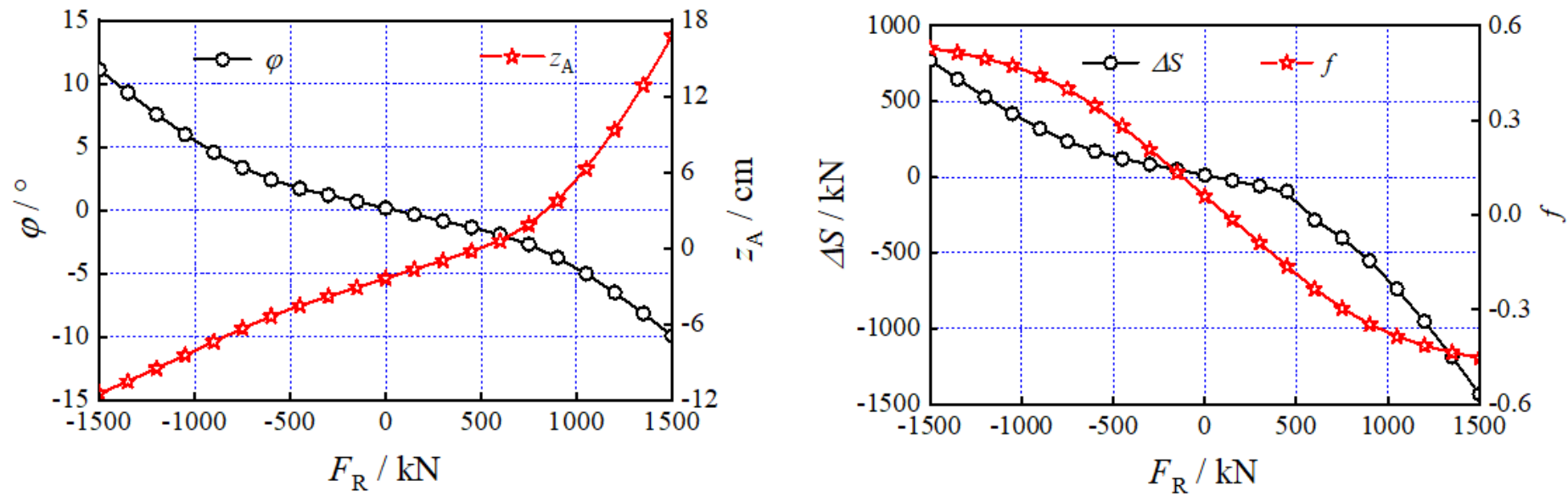

(a) Influence of tangential load on support rotation;(b) Influence of tangential load on support sliding

\section{Figure 12}

Influence of tangential load of roof on support stability ( $\mathrm{h}=4 \mathrm{~m}$ ) 

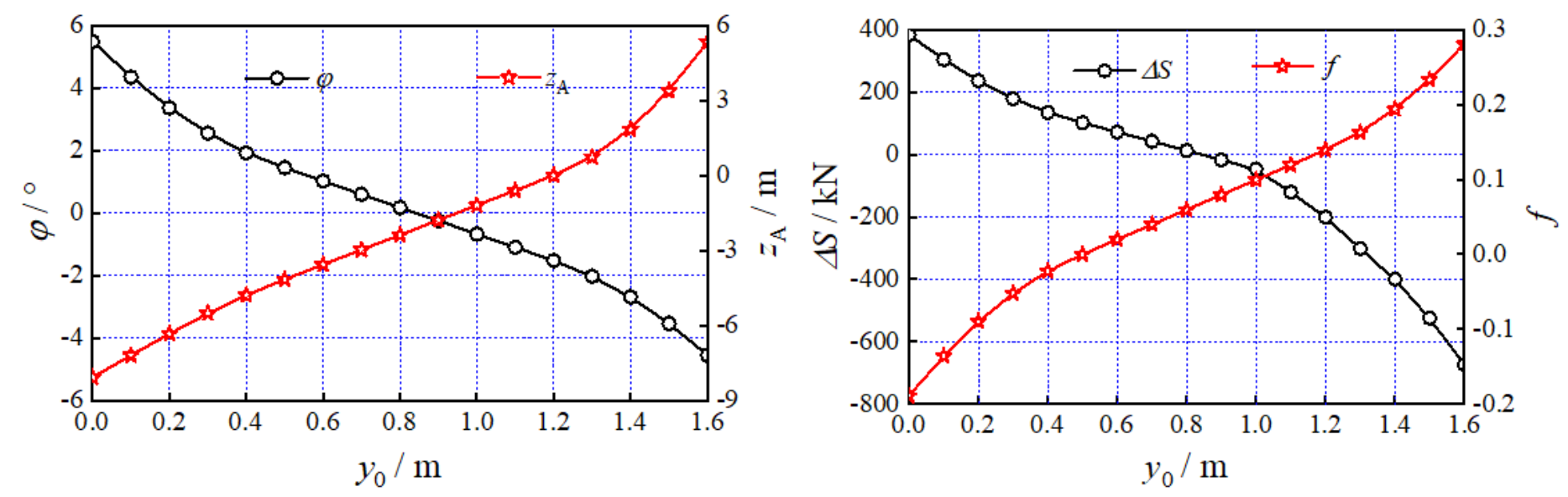

(a) Influence of action position on support rotation;(b) Influence of action position on support sliding

Figure 13

Influence of action position of normal loading on support stability $(\mathrm{h}=4 \mathrm{~m})$
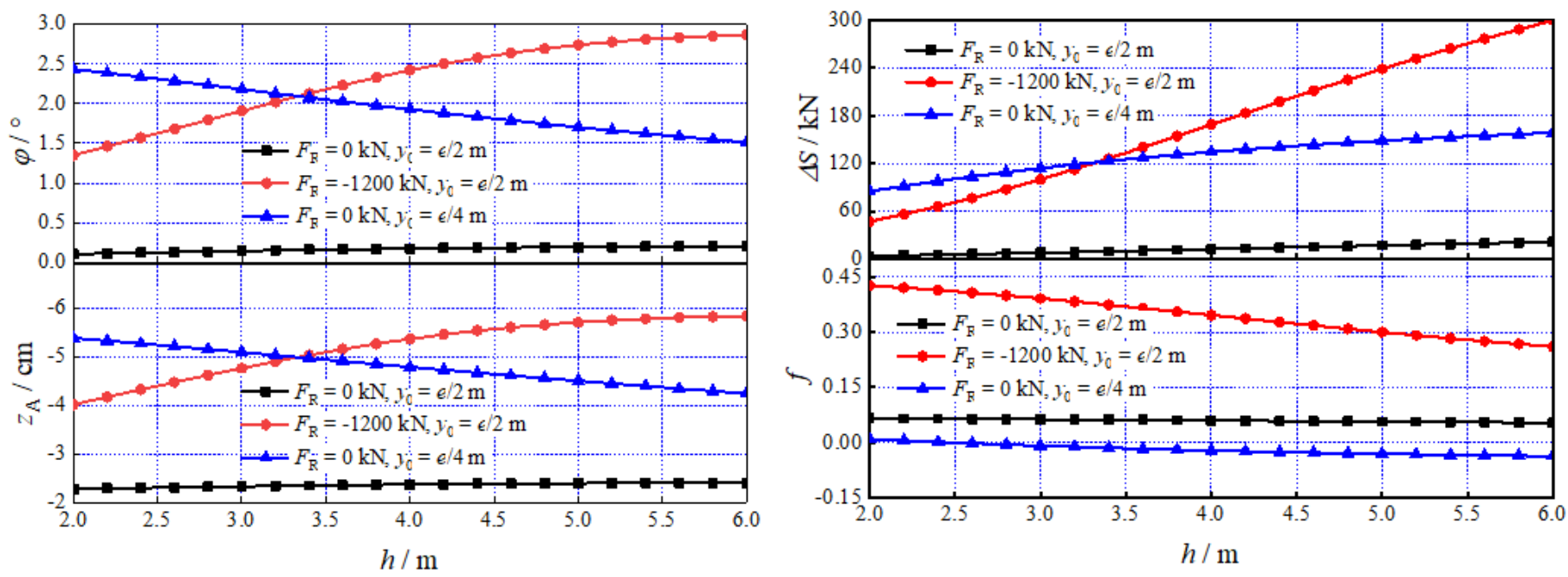

(a) Influence of mining height on support rotation;(b) Influence of mining height on support sliding

Figure 14

Influence of mining height on support stability $(P=5,000 \mathrm{kN})$ 